\title{
Optimal Synthesis of Multi-Effect Evaporation Systems of Solutions with a High Boiling Point Rise
}

\author{
Jaime Alfonzo Irahola \\ Universidad Nacional de Jujuy \\ Argentina
}

\section{Introduction}

In the past, optimization had been studied only for typical flowpatterns like forward and backward feed. To make the choice between them, simple rules were applied based on the viscosity and the temperature of the initial dilute solution $\left(\mathrm{T}_{\mathrm{F}}\right)$. Thus, forward feed was usually favored for the evaporation of low-viscous hot solutions featuring a temperature $T_{F}>T_{p}$, where $T_{P}$ is the desired temperature of the final product. By doing so, the liquid heating load is largely cut down. In turn, backward feed was recommended for heavyviscous cold liquors.

Moreover, a few contributions to the optimal synthesis of multiple effect evaporator systems (MEES) have so far been published. Most of the previous papers was focused on the analysis rather than the synthesis of evaporation systems. They generally assumed that important structural variables like vapor and liquid flowpatterns and the number of effects are all known data though they drastically change the performance of a MEES.

Nishitani and Kunugita (1979) first presented a multiobjective problem formulation to determine the optimal flowpattern of a multiple-effect evaporator system. However, they did not consider stream mixing/splitting. In addition, the solution method performed oneby-one the simulation of the MEES for all possible flowpatterns. More recently, Hillebrand and Westerberg (1988) developed a simple model to explicitly compute the utility consumption for multiple-effect evaporator systems exchanging sensible heat with outside streams. In turn, Westerberg and Hillebrand (1988) introduced the concept of "heat shunt" to derive the best liquid flowpattern in a heuristic way. Nonetheless, major assumptions like constant boiling point elevation, no liquid bypassing and negligible heat of mixing somewhat limit the applicability of their findings.

To resolve the problem presented here has been used a mathematical model rigorous previously developed (Irahola \& Cerdá, 1994). It considers the possibility of optimizing the variables that you want to. This has allowed that the model is used to solve various types of problems, namely: simulation, optimization, optimal synthesis and optimum partial reengineering restrictive of multi effect evaporation system (MEES) (Irahola, 2008). The mathematical model developed is the MINLP and solved using commercial software. The approach was successfully applied to three industrial problems. Depending on the feed and 
the product temperature, the optimal configuration uses a distinct liquid flowpattern that often differs from the conventional forward and backward feed and leads to reasonable savings (Irahola \& Cerdá, 1996)

Among the results should be noted that: the splitting of the flow of live steam can be a better alternative than the traditional cascade of steam; the best fixed cost curve is not always a monotonous increasing; the correct distribution of the areas of the effects of the MEES, the appropriate operating conditions and the correct choice of liquid and vapor flowpatterns, are the determining factors in the optimal design of the MEES.

Perhaps the greatest disadvantage found using the method proposed here to solve the formulated mathematical model (MINLP type) for optimal synthesis of the MEES is the presence of numerous local optimal what makes it difficult to obtain optimal Global.

\section{Evaporation of an aqueous solution of caustic soda}

Among the solutions of industrial interest that present a high increase in boiling point are sodium hydroxide solutions (caustic soda). The concentration of these substances by evaporation, presents significant disadvantages due to the characteristics of the caustic solutions, namely:

- Have a high boiling point elevation (BPE) which implies a great loss in the temperature difference available.

- Concentrated solutions are highly viscous, which severely reduces the rate of heat transfer in natural circulation evaporators.

- They can have detrimental effects on steel, causing what is called caustic fragility. In addition, they may require removal of large amounts of salt when the solution is concentrated.

Since the transfer of heat $(\mathrm{U})$ of liquor film coefficient, depending on the speed of the caustic solution through tubes (among other variables), usually, seeks a high speed in order to obtain a large coefficient (Kern, 1999).

According to the literature, it has taken as standard for the concentration of caustic soda, a evaporation system of two or three effects operate in backward feeed (Kern, 1999). In this study, found that the structure in counterflow or backward feed, obviously presents a high performance, but is not the best. In order to confirm what was said, is going to solve a problem.

\section{Optimal synthesis of a multi-effect evaporation system for the concentration of caustic soda}

\subsection{Problem}

Find the optimal MEES to concentrate $30040 \mathrm{lb} / \mathrm{h}(13626 \mathrm{~kg} / \mathrm{h})$ of an aqueous solution of sodium hydroxide from 10 to $50 \%$ by weight. The type of used evaporator is long vertical tube with forced circulation. Available in the plant: live steam boiler to 63.69 Psia (4.48 $\mathrm{kg} / \mathrm{cm} 2)$. The allowable minimum absolute pressure in an effect is of 1.942 Psia (0.1365 $\mathrm{kg} / \mathrm{cm} 2$ ) (Geankoplis, 1983). 


\subsection{Mathematical model}

The scope of the rigorous mathematical model is limited by the following assumptions adopted in the formulation:

a. In each effect, the vapor and liquid phases are in equilibrium.

b. A solid phase never arises in any effect.

c. The impact of the hydrostatic head on the liquid boiling point is neglected.

d. There is no leakage or entrainment.

e. Heat losses from any effect need not be considered.

f. The steam always condenses completely.

g. Subcooling of the condensate is very small.

$\mathrm{h}$. Flow of noncondensables is negligible.

i. The concentrated final product is withdrawn from a single effect which in turn does not transfer liquid to any other one.

j. If necessary, you can use a heat exchanger or condenser so that the product go out to the preset temperature $(\mathrm{Tp})$.

k. Not consider any type of pump between the effects.

To solve the mathematical model and find the optimal design should be available before, the mathematical expressions for all dependent variables: enthalpy of steam $(\mathrm{H})$, enthalpy of solution of soda caustic $(\mathrm{h})$, latent heat of vaporization of the water $(\lambda)$, overall heat transfer coefficient (U), temperature of the solution in the evaporator $(\mathrm{T})$ and costs of forced circulation evaporator, barometric condenser multijet, surface condenser and heat exchanger. In general, useful information is available in graphics, which presented various authors cited in the bibliography, but there are no equations of those curves. These situations and other problems are resolved below. According to Standiford (1963), in forced circulation evaporators, film transfer coefficient $(\mathrm{h})$ on the side of the liquid, can be calculated from the conventional Dittus-Boelter equation for forced circulation when there is no boiling.

$$
\frac{h D}{k}=0.0023\left(\frac{D G}{\mu}\right)^{0.8}\left(\mu \frac{C p}{k}\right)^{0.4}
$$

If there is this equation for two points and combine both equations, you can find the functionality of $\mathbf{h}_{\mathbf{1}}$ with respect to another point (2) as:

$$
h_{1}=h_{2}\left(\frac{\mu_{2}}{\mu_{1}}\right)^{0.4}\left(\frac{C_{p 1}}{C_{p 2}}\right)^{0.4}
$$

As the overall heat transfer coefficient $U$ is practically determined by the film coefficient $h$ fluid side, the above equation can be used to obtain a correlation for $\mathrm{U}$. In Geankoplis for $\mathrm{T}=105^{\circ} \mathrm{F}$ and $\mathrm{X}=0.5$, data is $\mathrm{U}=400\left(\mathrm{Btu} / \mathrm{h} \mathrm{ft}{ }^{\circ} \mathrm{F}\right)$. $\mathrm{T}$ and $\mathrm{X}$ is obtained from a graph (Horvath, 1985) $\mu_{2}=22.84$ centipoise. Then, for five values of concentration and six temperature values are obtained from graphics (Horvath, 1985) the values of $C \mathrm{p}_{1}$ and $\mu_{1}$. With the data obtained can be calculated according to the above expression, the overall heat transfer coefficient $U_{1}$ with reference to $U_{2}$. Thus, $U$ is plotted vs. $X$ (Fig. 1) and $U$ vs. T (Fig. 2). Finally, using the triple $X, T, U_{i}$, can be found by regression, the functionality of $U$ in terms of concentration and temperature: 


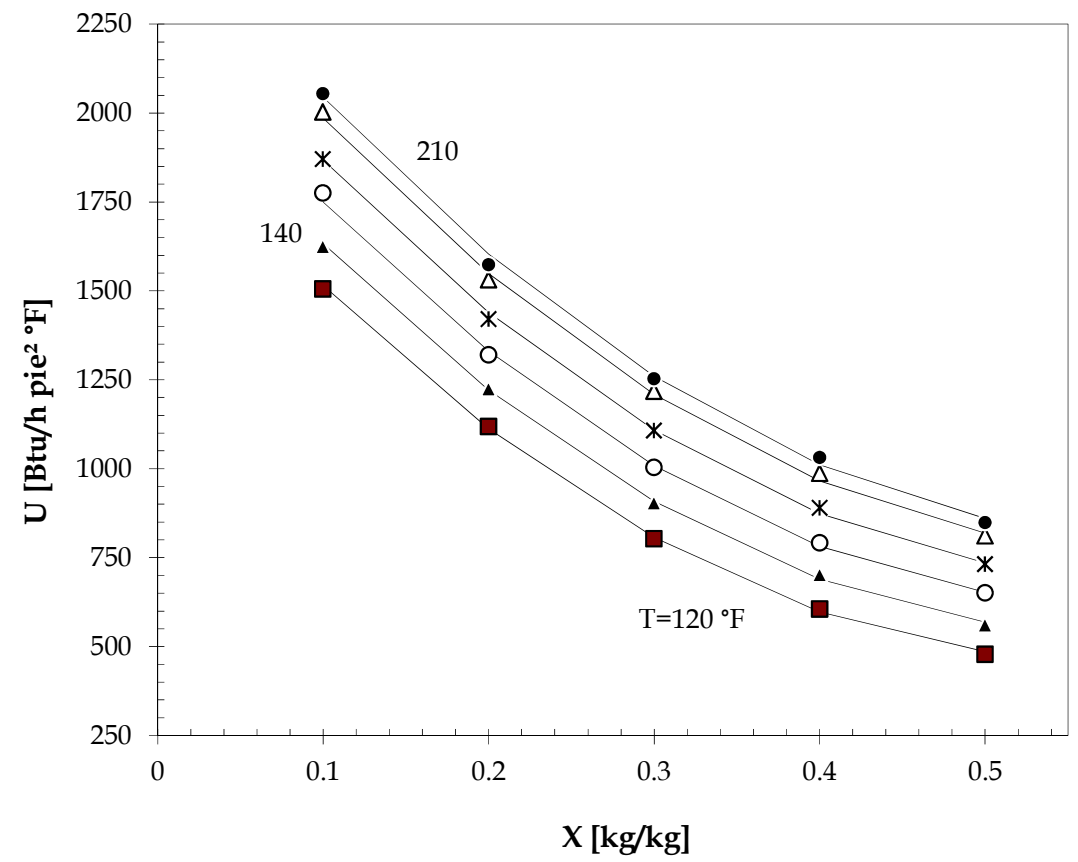

Fig. 1. Overall heat transfer coefficient correlation as a function of solute concentration.

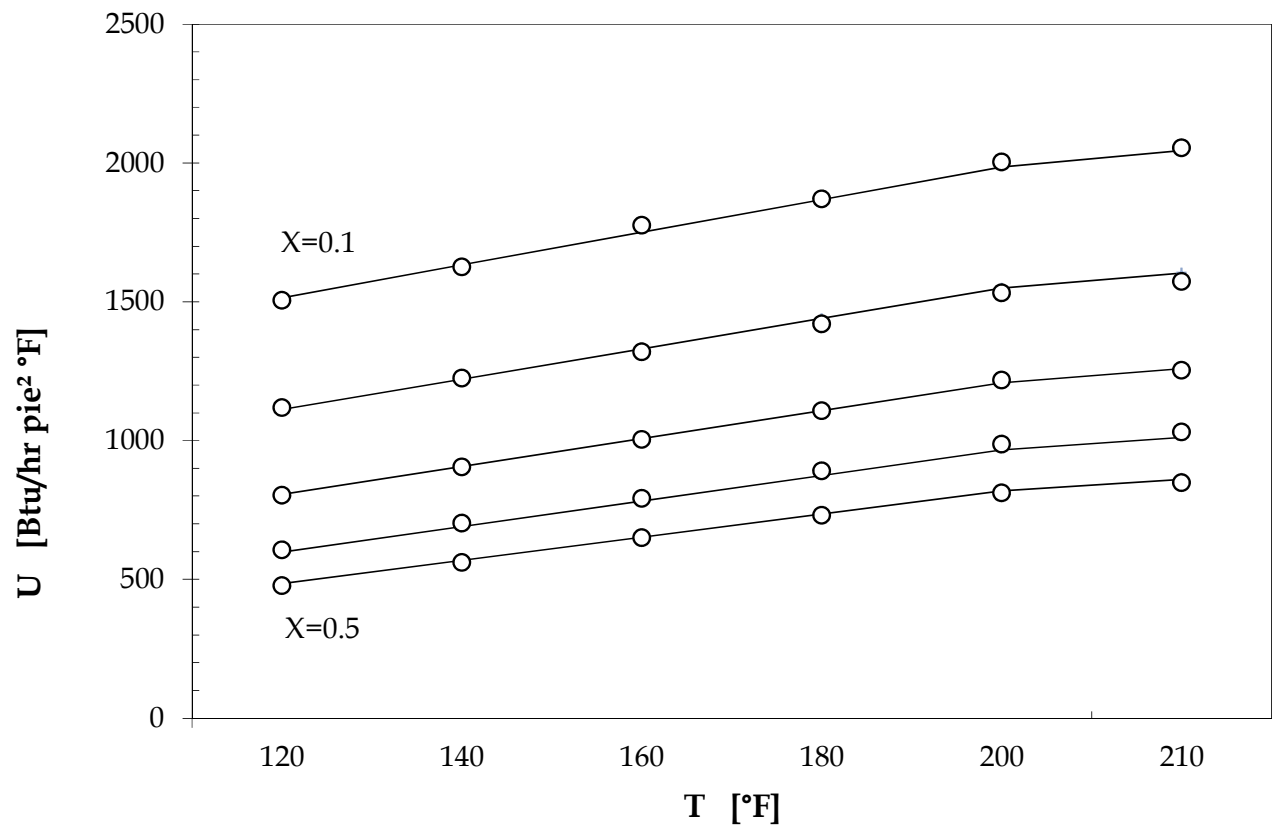

Fig. 2. Overall heat transfer coefficient correlation as a function of temperature. 


$$
\begin{gathered}
U=1254.780865-4954.6700 X+4832.059524 X^{2}+6.321549 T \\
-4.30974 X T\left[\frac{B t u}{h f t_{2}{ }^{\circ} F}\right]
\end{gathered}
$$

where: $\mathrm{X}$ : mass fraction and $\mathrm{T}[=]^{\circ} \mathrm{F}$

The regression function is chosen to achieve maximum correspondence with the data, but at the same time trying to maintain, if possible, the simplicity. Nevertheless, we could not avoid the bilinear term. Figures 1 and 2, you can appreciate the good fit of the correlation found for $\mathrm{U}$.

Also, to represent the enthalpy of solution, depending on the concentration and temperature, it became a non-linear regression with data from Foust (1980) (Fig. 3):

$$
\begin{gathered}
h=-10.250000-319.591837 X+939.795918 X^{2} \\
+0.963929 T-0.335714 X T\left[\frac{\text { Btu }}{l b}\right]
\end{gathered}
$$

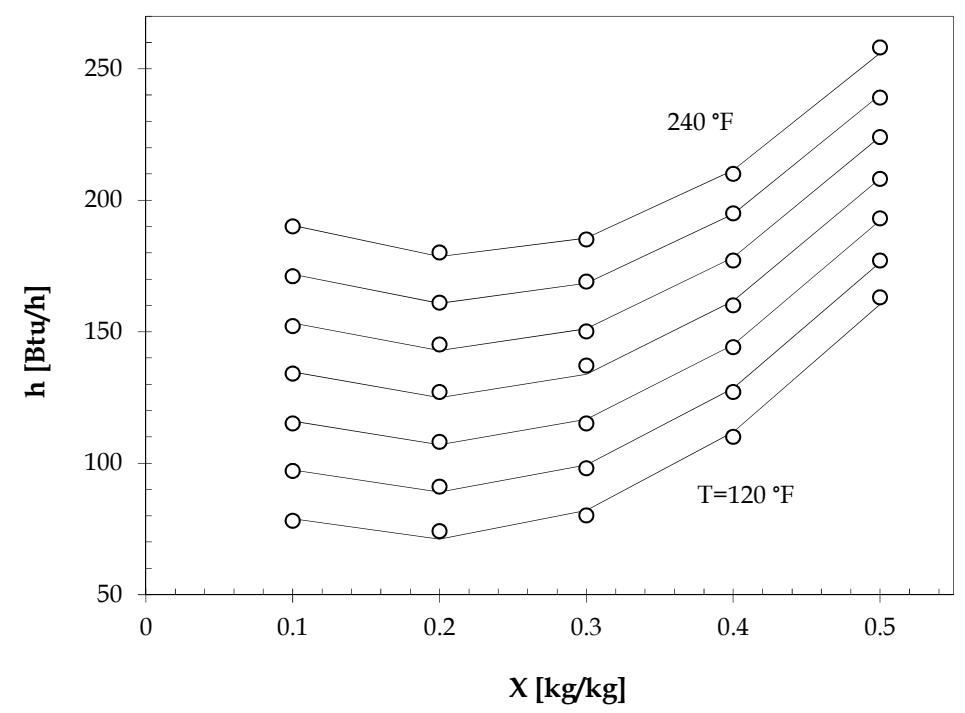

Fig. 3. Enthalpy of solution

The functional expression of the cost of barometric condenser multijet $\left(\mathrm{C}_{\mathrm{CBM}}\right)$ is obtained by regression analysis of the chart presented by Peters (1991). Again, searching for mathematical expressions that minimize non-convexities of the mathematical model, we found that a quadratic expression represents excellent, the cost curve in the range of work desired (Fig. 4) (1992):

$$
C_{C B M}=4,753104+2,480885 w+0,281818 w^{2}\left(10^{3} U S D\right)
$$

Where: $\mathrm{w}[=]$ gpm. The flow rate of cooling water $(\mathrm{w})$ required in the condenser is directly given by (Kern, 1999): 


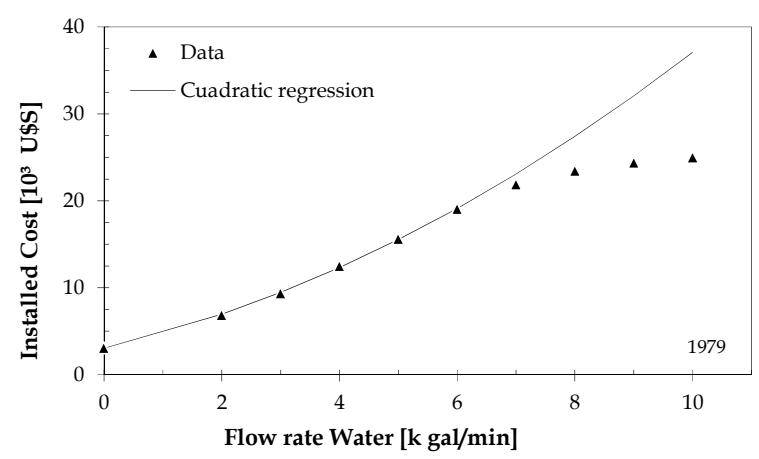

Fig. 4. Installed Cost of multijet barometric condenser.

$$
w=\frac{Q}{500\left(T_{s}-T_{w}-t_{a}\right)}(\mathrm{Gpm})
$$

where:

$Q=$ heat load, Btu / h

$T_{S}=$ temperature of saturated steam, ${ }^{\circ}-\mathrm{F}$

$T_{w}=$ temperature of cooling water, ${ }^{\circ}-\mathrm{F}$

$t_{a}=15^{\circ}-\mathrm{F}=$ degree of approximation at $T_{s}$

The cost of forced circulation evaporator is obtained based on information reported by Maloney, 2008:

$$
C E_{F C}=2420.5 A^{0.7121} U \$ S
$$

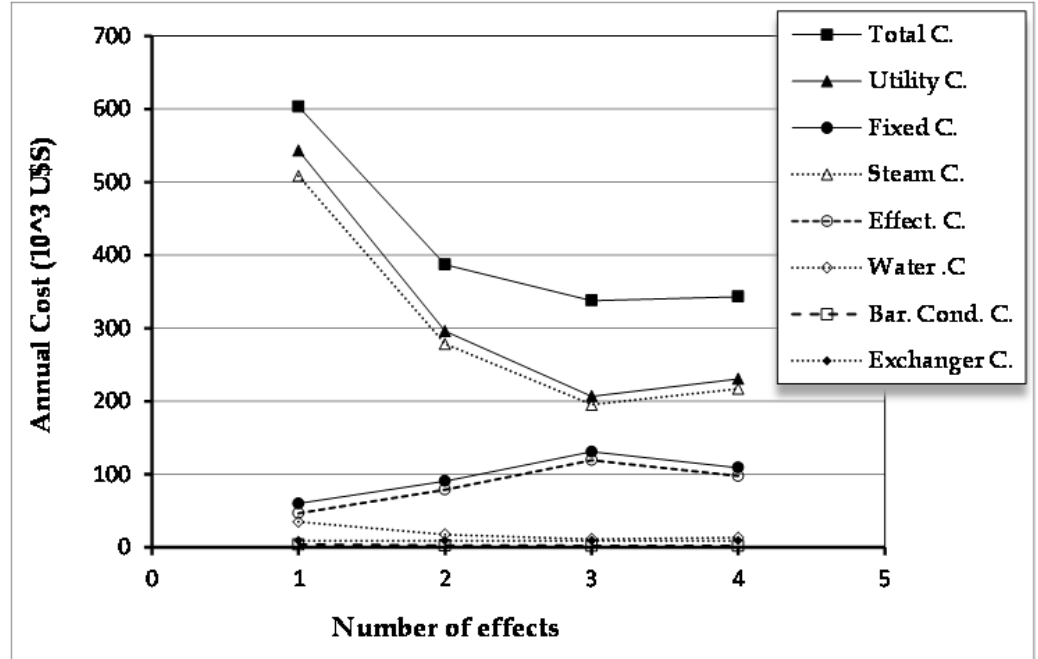

Fig. 5. Evolution of total operating costs. 
The information of the data used in the resolution of the problem is presented in table 1 . Also, the thermodynamic properties of the remaining functions and costs of services and equipment are presented.

In order to consider probable situations that could be presented in the industry, will study the cases in which the temperature of the weak solution (feed) is equal, higher or lower than the temperature of the strong solution (product). In the three cases, only change the values of the inlet of the weak solution temperature. The rest of the parametric conditions remain fixed.

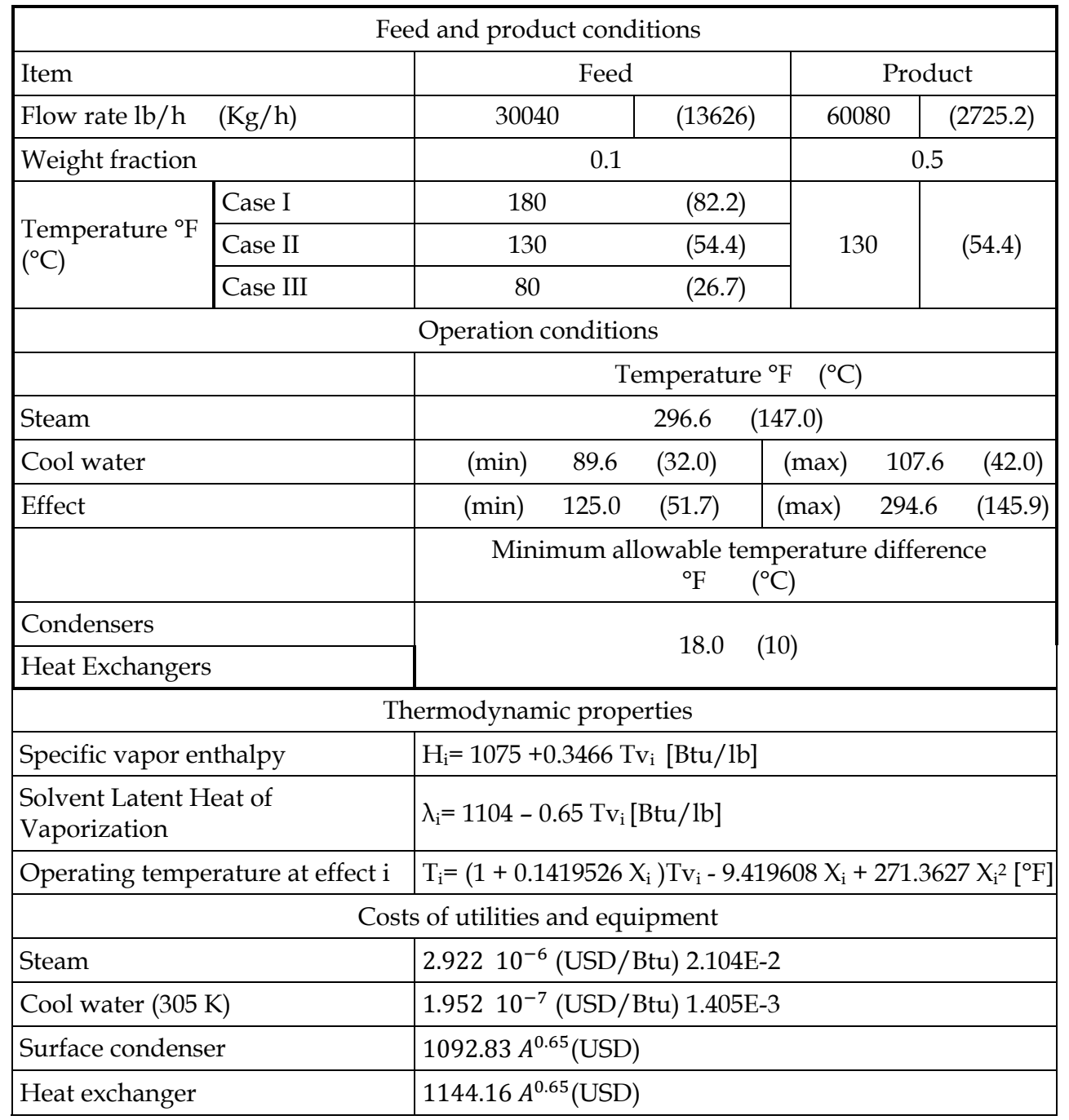

Table 1. Data for example and, functional expression of thermodynamic properties and the costs of utilities and equipment. 


\section{Analysis and discussion}

\subsection{Case I. Feed temperature higher than the temperature of the product $\left(T_{F}>T_{P}\right)$}

\subsubsection{Comparative analysis of the optimal solution found}

Adopted $\mathrm{T}_{\mathrm{F}}=180^{\circ} \mathrm{F}\left(82.2^{\circ} \mathrm{C}\right)$. Coinciding with the generally accepted criterion of optimality for the evaporation of caustic soda, has been found that the optimum number of effects of the MEES is equal to three (Fig. 5). However, a mixed structure $\{2,1,3\}$ has been found in the path of the current liquid instead of backward feed. The feed stream enters to the effect 2 and then continuous countercurrent to the effect 1 . Then go out and circulates in forward feed to the effect 3. (mixed liquid flowpattern). In this new structure that is presented (Fig. 6), we see significant increases in boiling point of the solution: $10.5^{\circ} \mathrm{C}$ and $40^{\circ} \mathrm{C}$, in effects 1 and 3 respectively.

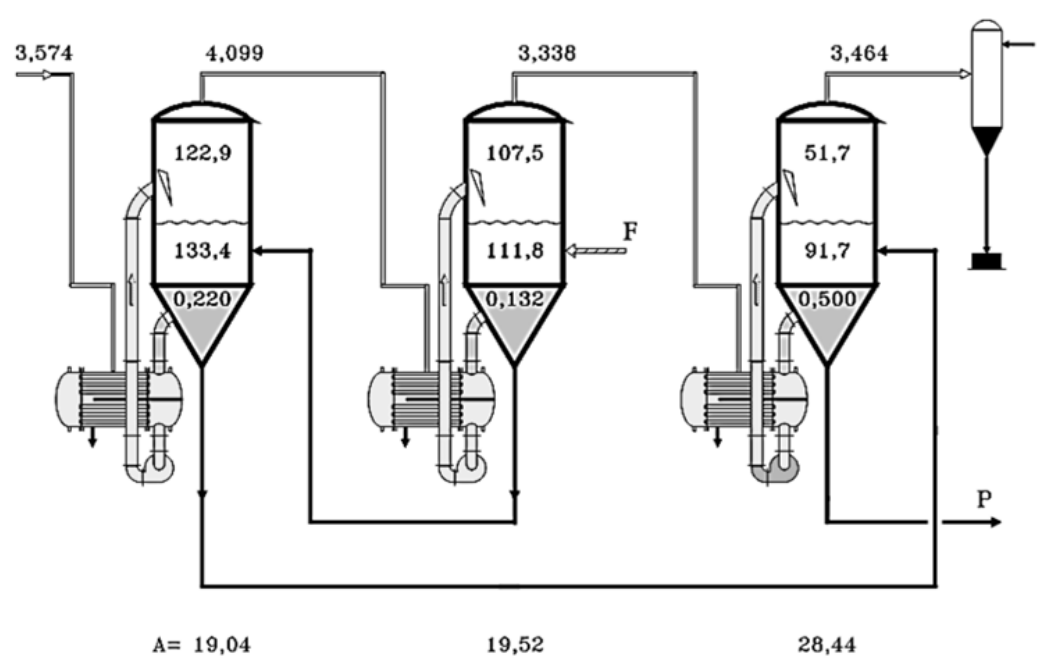

Fig. 6. Optimal configuration three-effect MEES. (TAC=337835 USD)

The optimal solution will be the one with the lowest total annual cost (TAC). From this point of view, the classical structure proposed as an optimum solution: evaporation system of three effects of equal area arranged backward feed (BFA), is $4.31 \%$ more expensive than the optimal solution (SO) (Fig. 7). More, even if it is allowed to in the structure backward feed, the effects have distinct areas (BF), do not get a better result that the optimal solution found. The difference in cost is $4.03 \%$. In the figure 7 , we also present results for a forward feed evaporation system. This structure, in its classic form forward feed with effects of equal area (FFA), is $7.91 \%$ more expensive. Which could corroborate, in some way, because in the past the BFA structure was preferred. If is allowed that the effects have different areas in the structure forward feed (FF) is very interesting the result obtained. The correct distribution of areas has led to a decrease in the total cost. The decrease is so great that, now, the FF structure is better than any of the above structures in backward feed. Its total annual cost (TAC) is only $2.95 \%$ greater than the of the optimum solution found (Fig. 7). In general, it appears that whatever the structure of MEES, the operating cost is significantly greater than the fixed cost (Fig. 8). It is approximately $65 \%$ of the total cost. 


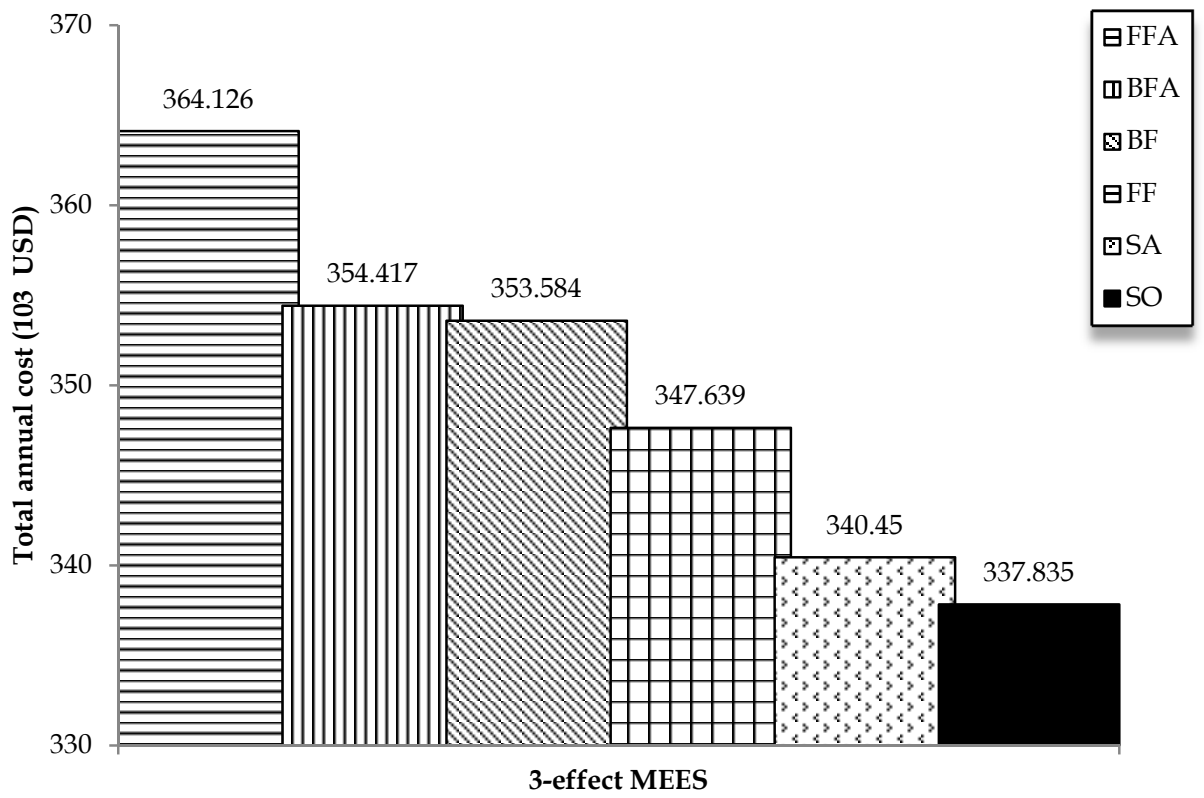

Fig. 7. Comparison with Typical Flowpatterns.

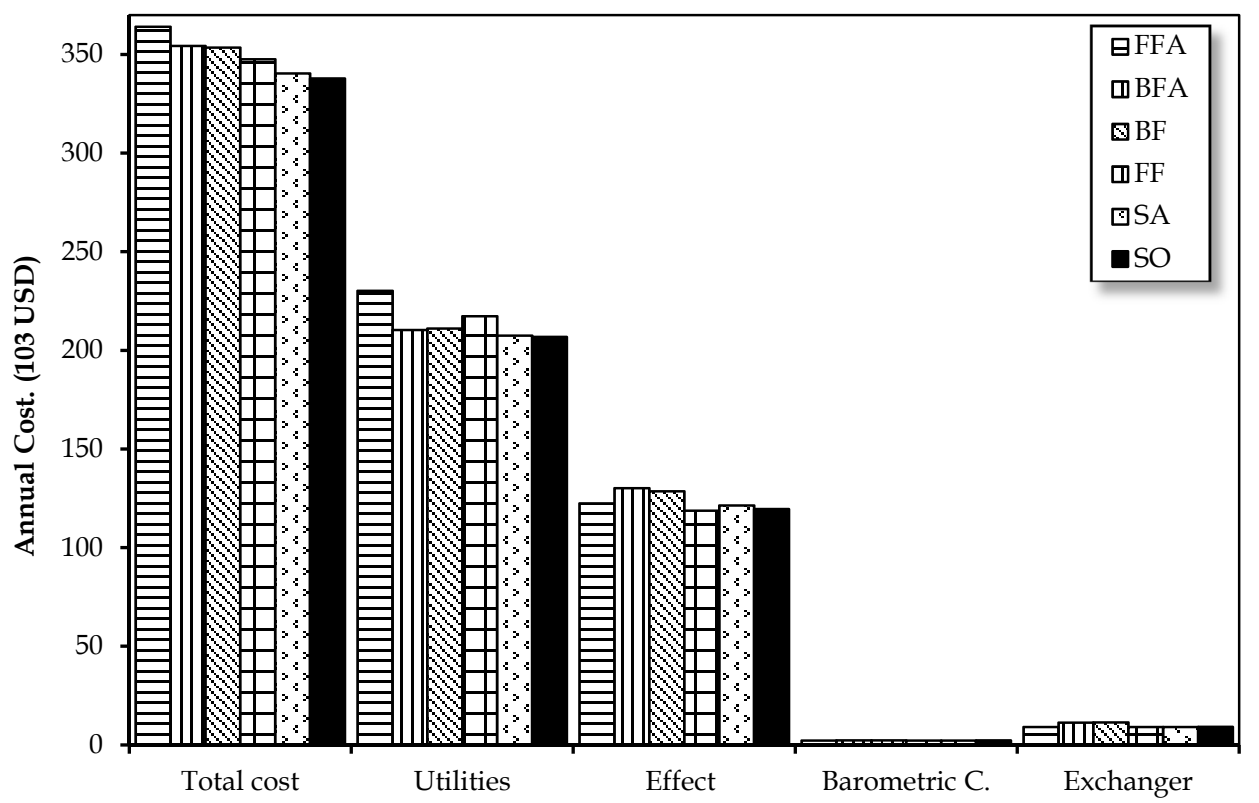

Fig. 8. Relative incidence of Operating and fixed Costs 


\subsubsection{Impact of the flow pattern}

In this case, the trajectory of the liquid stream is the determining factor in the performance of a given MEES. The benefit achieved is even greater than obtained by allowing the effects having different areas with each other. That said, is based on the result of the structure SA. This has the same flow pattern that the optimal solution, but the effects of evaporation system are of equal area. The increase in cost is only $0.8 \%$ compared to MEES optimum (Fig. 7). From the practical point of view, the alternative SA may be the best option.

\subsubsection{Profiles of the structural and parametric variables}

As it will be seen later, only in this case it can be seen some regularity in the curves of the structural and parametric variables. Furthermore, after reaching the optimal point generally the next curve is anomalous with respect to the preceding ones. In the last effect occurs the maximum concentration jump $(\Delta X)$ of the solution (Fig. 9). At the same time, it has the maximum area as shown in the curves of the 1 to 4 -effect optimal MEES (Fig. 10). The flow rate of steam produced in the effects is approximately the same. However, this does not apply to MEES with greater number of effects than the optimal. (Fig. 11). The profile of the temperature to the optimum MEES of a different number of effects, does not have a regular aspect. However, the maximum temperature jump occurs in the last effect (Fig. 12).

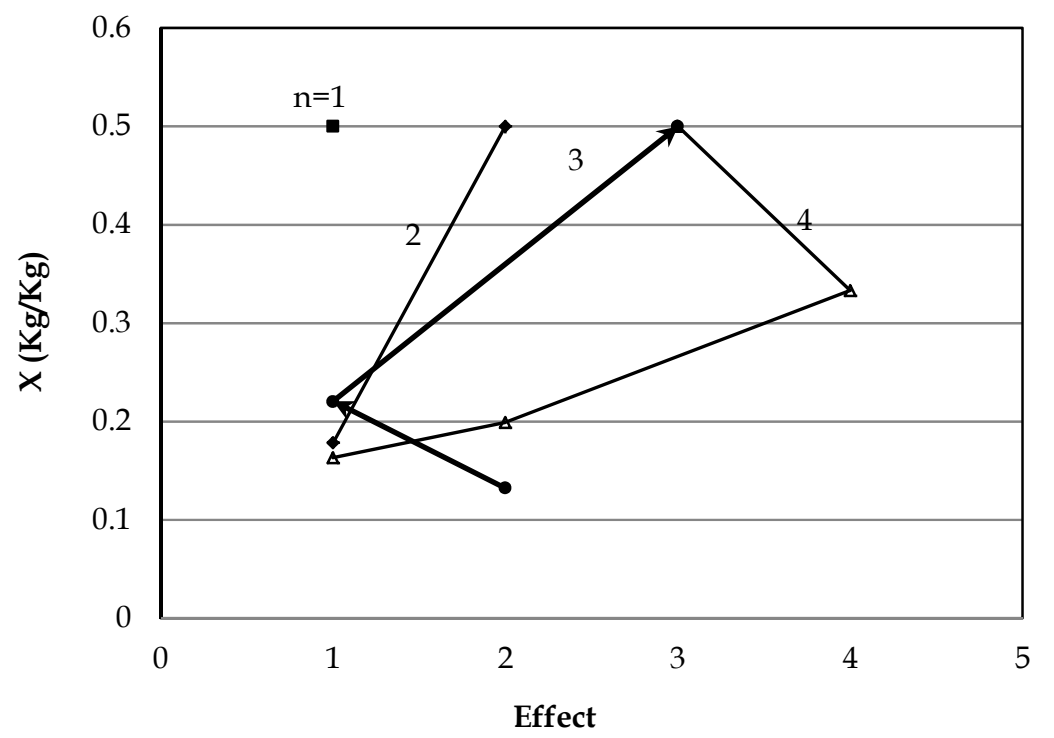

Fig. 9. Concentration profiles in the 1 to 4 -effect MEES. (n: number of effects) 


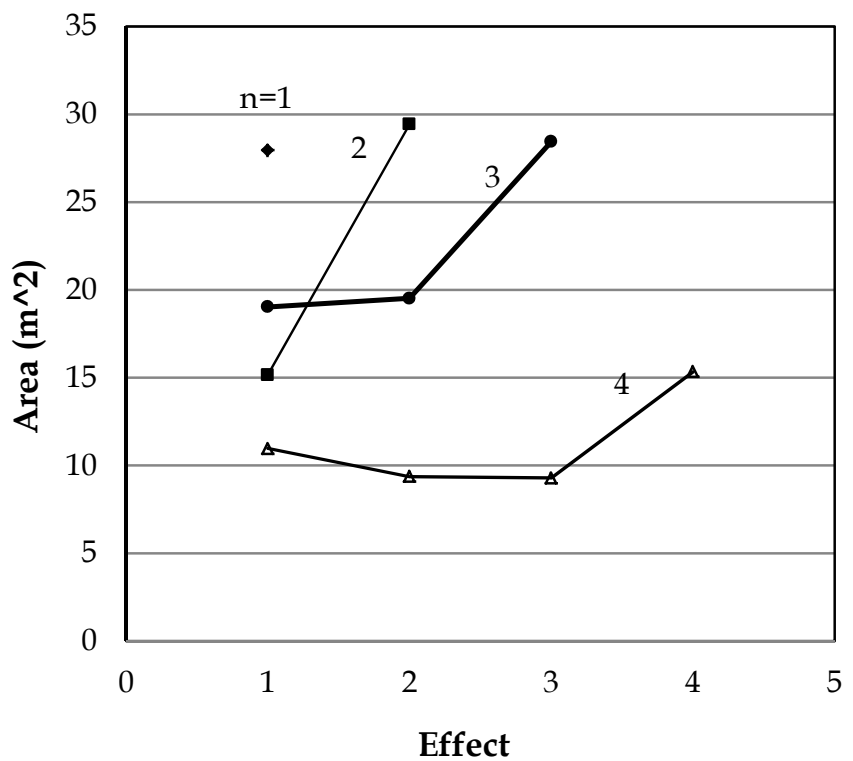

Fig. 10. Area profiles in the 1 to 4 -effect MEES (n: number of effects).

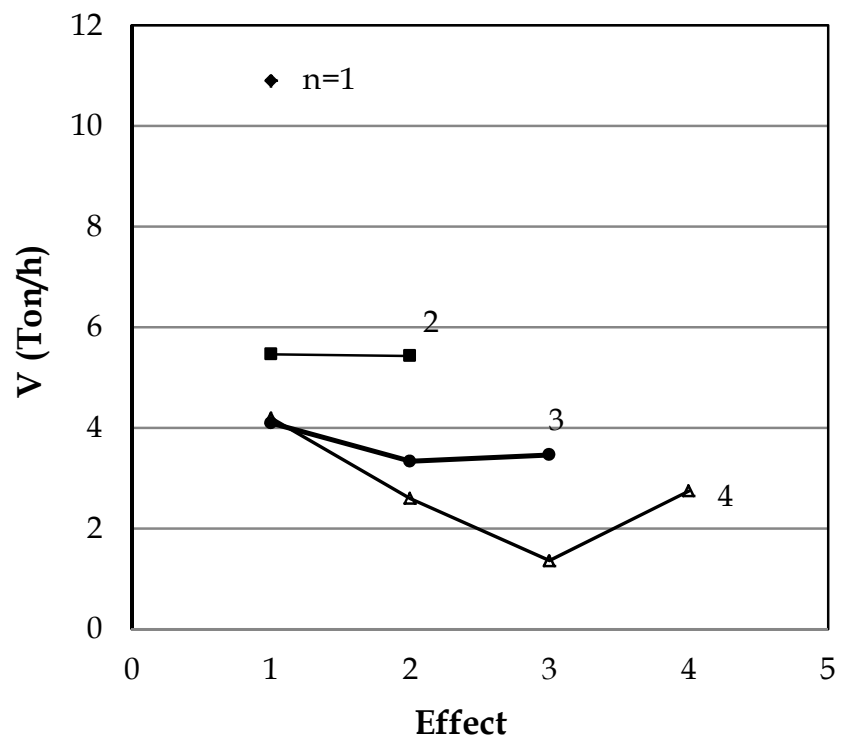

Fig. 11. Flow rate profiles in the 1 to 4 -effect MEES (n: number of effects). 


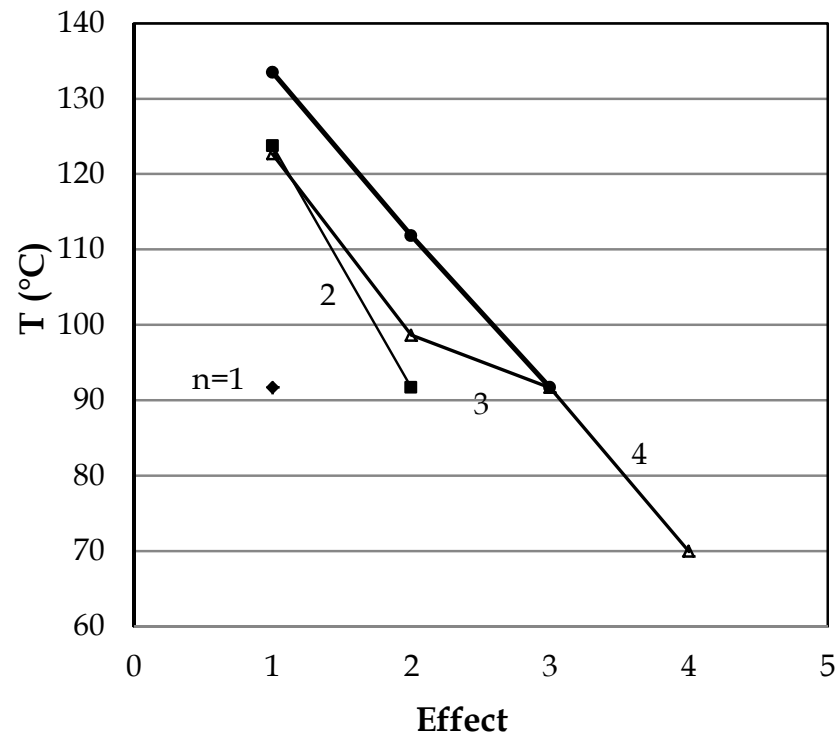

Fig. 12. Temperature profiles in the 1 to 4 -effect MEES (n: number of effects).

\subsection{Case II. Feed temperature equal than the temperature of the product $\left(T_{F}=T_{P}\right)$}

\subsubsection{Impact of the splitting of the live steam flow rate on the optimal solution}

The result obtained when $\mathrm{TF}=\mathrm{TP}$, is different, not only to the found for the case $\mathrm{I}$, but also with respect to the classical position. Found structure is highly innovative and simple in its conception.

If you look at the evolution of the total annual cost (TAC) curve of the 1, 2, 3, 4 and 5 effect Optimal MEES, it was found that the four-effect MEES is that of lower cost (optimal quasiglobal) (Fig. 13). The flow pattern is backward feed and in this aspect, this result coincides with the classical motion, but not with the number of effects: proposed here a four-effect MEES, instead of three. However, this new proposal, would not be really the best alternative, if it was not associated to the new steam flow pattern proposed (Fig. 14). It emphasizes, splitting in the live steam flow pattern, it enters parallel to the effects 1 and 2; the by-passing effect 2 by the vapor stream from effect 1 and finally, the mixing of vapor streams from effects 1 and 2 for heating effect 3 .

Against, this new trajectory of the flow of steam, first doubt that occurs, is the performance of this configuration against the unifilar cascade of high thermodynamic efficiency.

\subsubsection{Comparative study of proposed flow pattern with respect to traditional configurations}

For the purpose of explaining the improvement achieved, compares the structure backward feed with effects of different areas (BF) and the optimal solution (SO). Both structures have equal number of effects and same trajectory of the liquid flow and only differ in the 


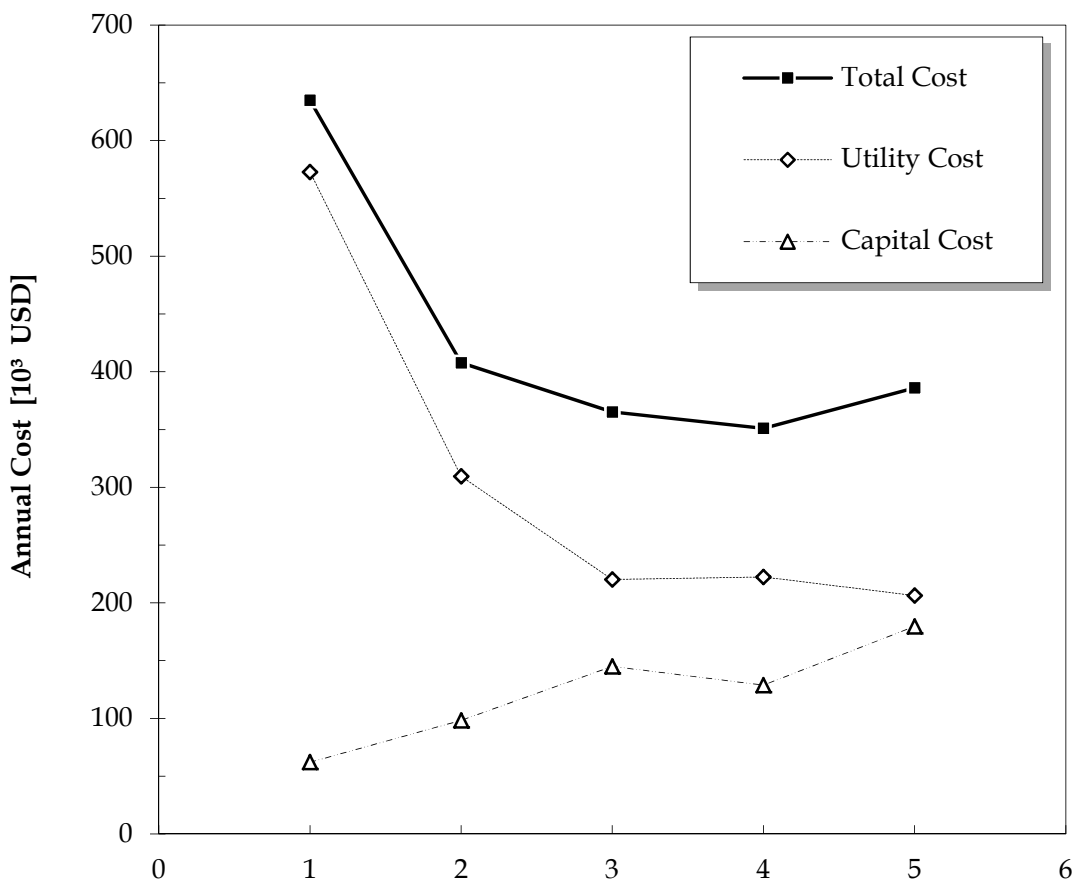

Number of effects

Fig. 13. Relative incidence of Operating and fixed Costs.

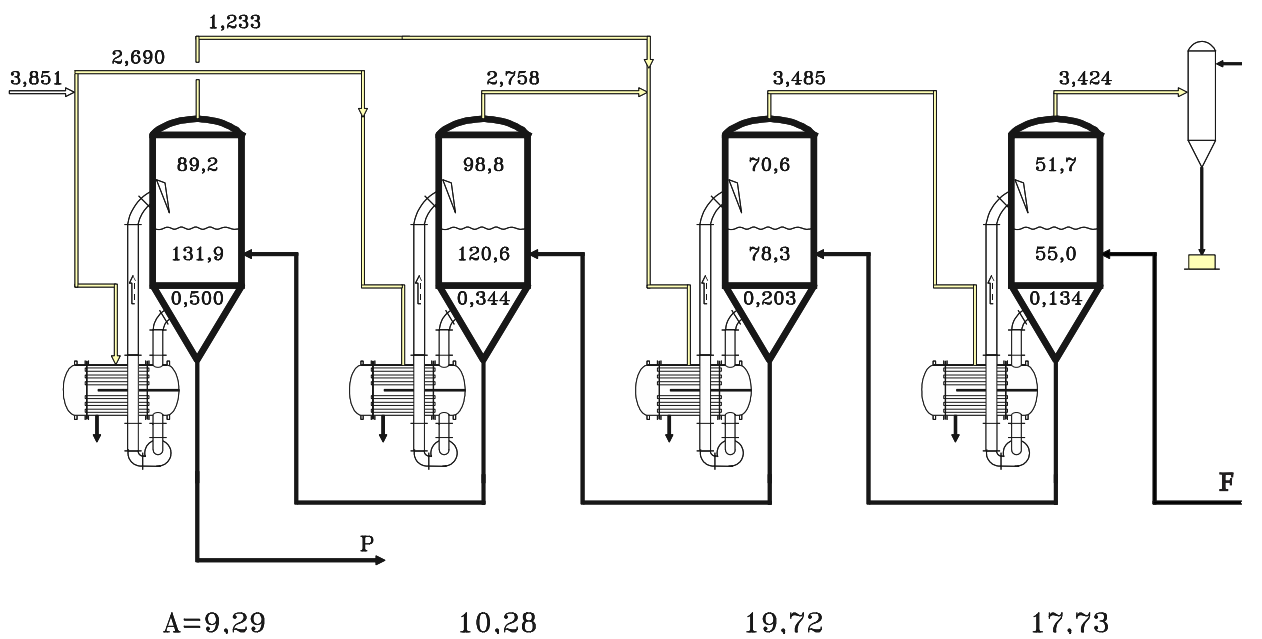

Fig. 14. Optimal configuration four-effect MEES. (TAC=351082 USD) 
trajectory of the flow of steam. Two comparisons were made: one relating to the cost of auxiliary services and the other with respect to the cost of the effects, which is almost all of the fixed cost.

\subsubsection{Energy efficiency and fixed cost of the traditional structure}

The BF structure has a higher efficiency since the cost of auxiliary services is 174963 USD, $21.30 \%$ less than the cost for the SO. On the other hand, the cost of the effects is 193008 USD, i.e. $167,8 \%$ of the respective cost observed in SO. The net result of the comparison of the total costs, indicates that the BF structure is $8.9 \%$ more expensive than SO. With these results, following the classical position we can say, that BF 4 effects is not better than the optimum found (SO), because the MEES should be a structure BFA 3 effects, not four, which was used to compare. Therefore, will be then verified the validity of this rule, for the case study.

\subsubsection{Difference in the number of effects due to non-traditional flow patterns}

The optimal number of effects found by the mathematical model does not coincide with the optimal number for BFA and FFA traditional structures or even structures BF and FF. This explains why in the absence of a mathematical model to explore the multiple alternatives of design, the best answer to the problem was until now, a countercurrent system.

It was found that the optimum number of effects to structures backward feed and forward feed is 3. However, the developed model proposes the structure SO of 4 effects as the best solution. Therefore, to verify the quality of it, is advisable to compare the best results found for each structure.

\subsubsection{The optimal solution compared to traditional structures}

The total cost of the BFA MEES is $4.2 \%$ more than the optimal. Therefore, the structure and number of effects, traditionally proposed do not seem to be the most appropriate. Then, one might think that if you remove the restriction of equal area of the effects, could be improved, significantly, the current result. The results show that the BF structure of three effects is $4.1 \%$ more expensive than SO (Fig. 15). However, despite the difference in the number of effects, is convenient to analyze in more detail these recent results.

Structurally, BF and SO differ only in the flow pattern of steam. The cost of the auxiliary services of $\mathrm{BF}$ is $1.0 \%$ lower than the $\mathrm{SO}$. On the other hand, the fixed cost is $13.4 \%$ greater determining to SO submit one minor TAC (Fig. 16).

\subsubsection{Profiles of the structural and parametric variables}

This case is characterized because the profiles of the process variables, for the various intermediate optimal MEES, they have no similarity among themselves. In particular, notes that the optimal solution presents the most discordant curve with respect to the others.

The temperature profile is irregular with temperature differences between effects nonuniform, being the most important jump located between 2 and 3 effect, following the drop of temperature effects 3 and 4 , both heated with secondary steam. (Fig. 17). The greater temperature difference between the heating steam and the solution to evaporate, occurs in 


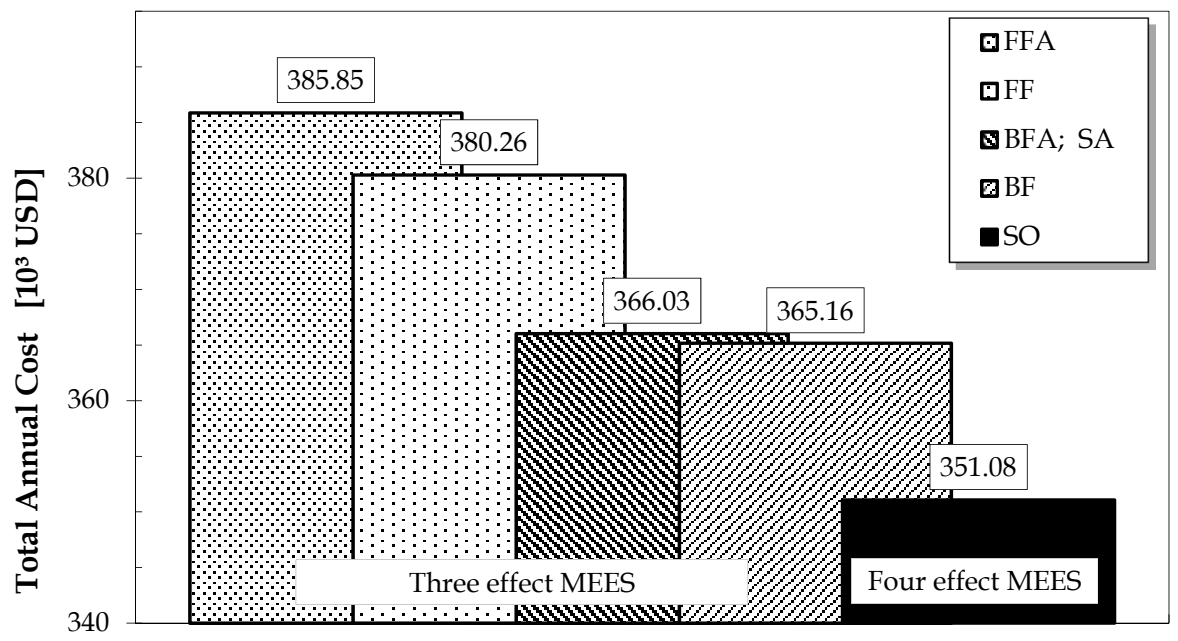

Estructure MEES

Fig. 15. Comparison with Typical Flowpatterns.

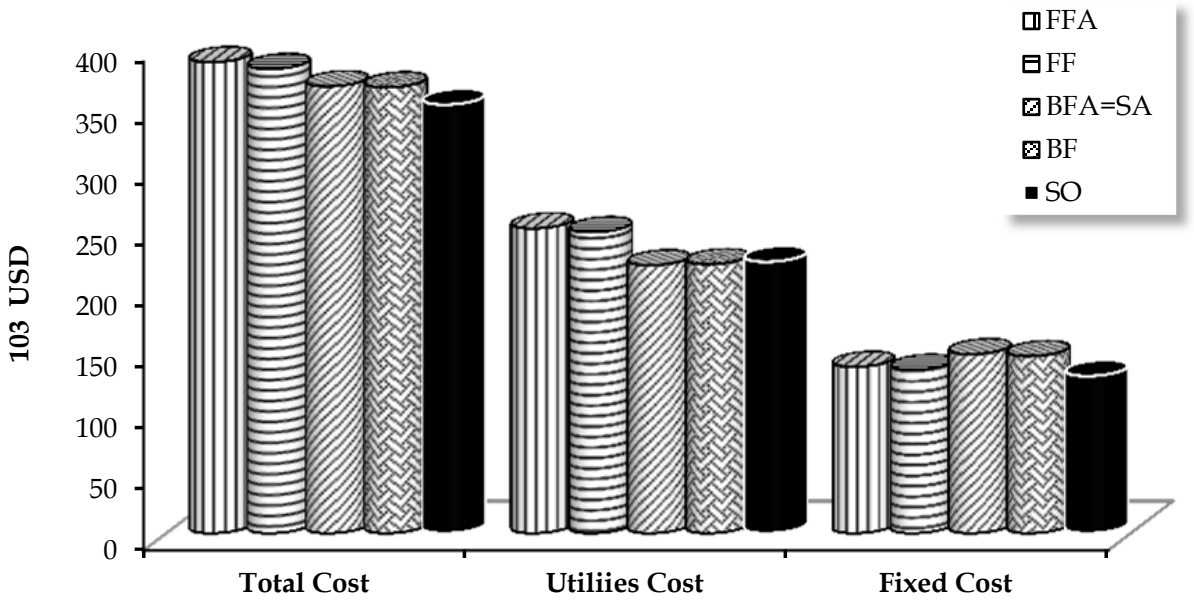

Fig. 16. Comparison with Typical Flowpatterns (Case II).

the effect 2 of the four effect MEES (Fig. 18), through the use of live steam in the effect. Thermal jumps that are achieved with the optimum structure are higher that in the triple and quintuple-effect MEES. In addition, it should be noted that the thermal jump in effect 2 is almost doubled with respect to other effects. 


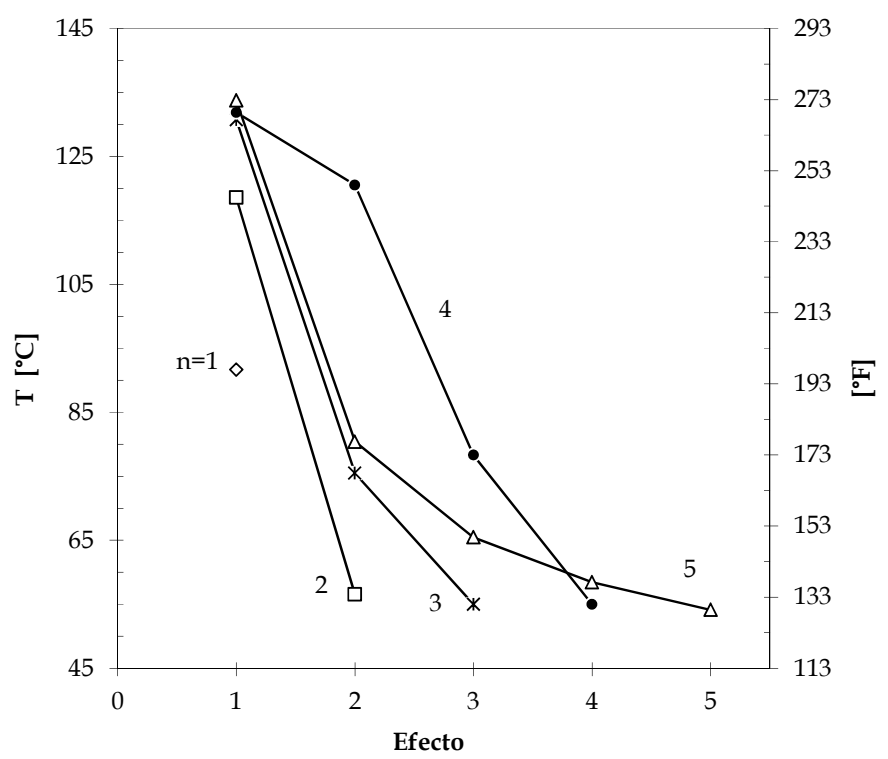

Fig. 17. Temperature profile optimal MEES for $n=1$ to 5 effects.

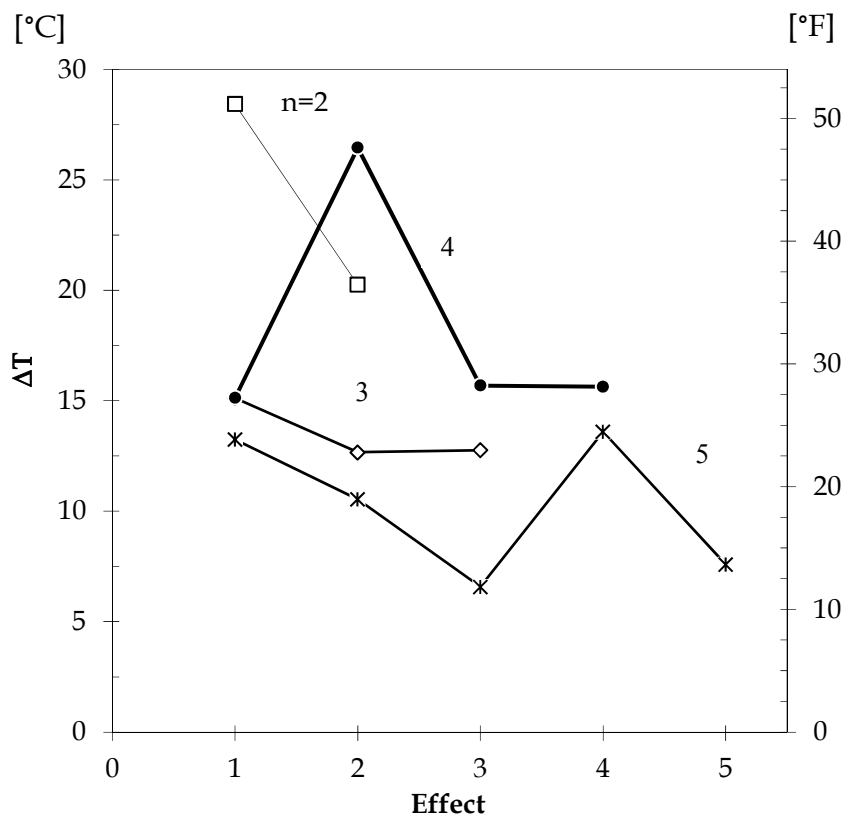

Fig. 18. Temperature difference profiles between the condensation and evaporation chambers in each effect for 2, 3, 4 and 5 effects. 
Similarly, the profile of the area for each MEES, is far from being uniform, with the highest values located in the lower thermal effects. (Fig. 19). Should be mentioned, that the problem had been resolved for a fixed range area $\left(100,1000 \mathrm{ft}^{2}\right)$.

The flow rate of solvent evaporated in each effect is approximately the same in the double and triple-effect MEES (Fig. 20), where the chosen structure is backward feed. But in the optimal solution and after this, the values of vapor flow rate are far from each other. Although it can be seen that, in SO the curve is regular and decreasing with temperature

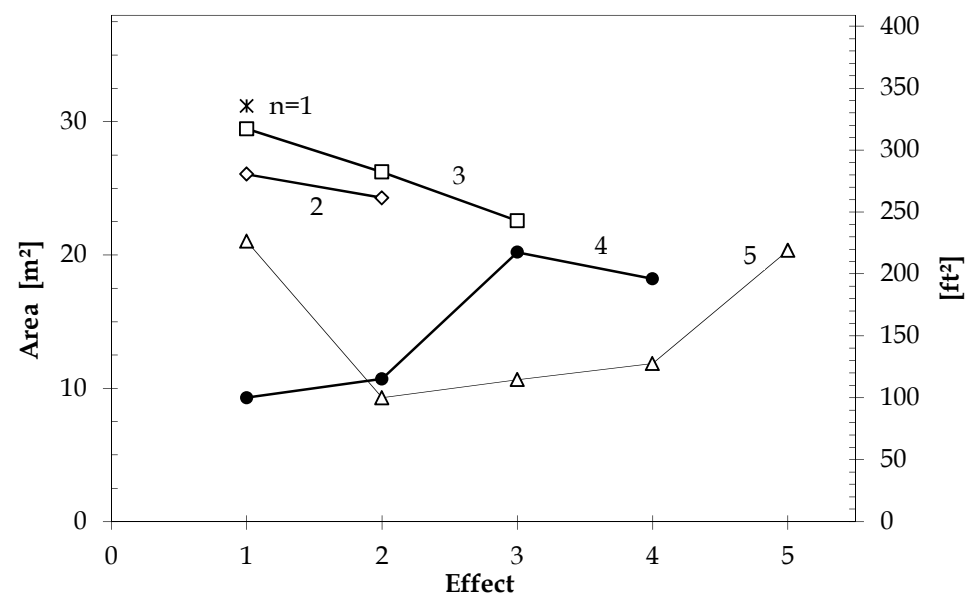

Fig. 19. Area profiles in the 1 to 5 effect MEES (n: number of effects)

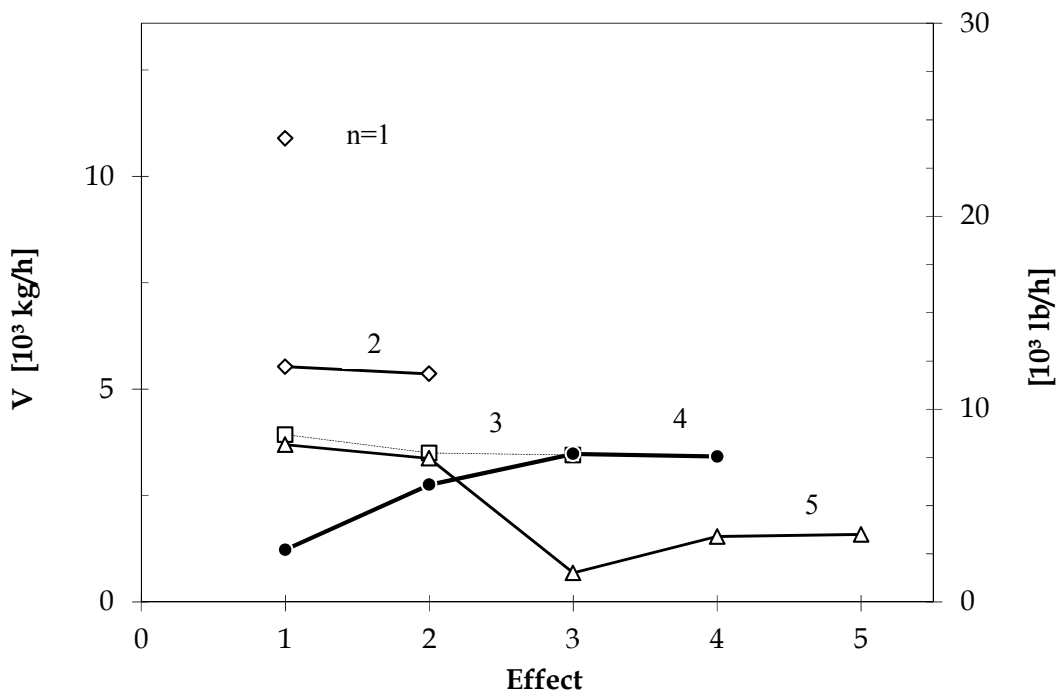

Fig. 20. Flow rate profiles in the 1 to 5 -effect MEES (n: number of effects). 
effects, i.e. the greater evaporated flow rate occurs in the effect 4 . The profile of the global coefficient $\mathrm{U}$ is similar: lower in effect 1 and higher in the effect 4 . It is important to clarify that, the values of the flow rate of steam produced in each effect are not directly indicative parameters. Yes it is a relative measure, for example, the percentage of the current liquid evaporates. Thus, the percentage amount of solvent evaporated, with respect to the flow rate of solvent that enters each effect, is maximum in the second effect $(41 \%)$, followed in decreasing order, the third effect (34\%), the first (31\%) and finally the fourth (25\%).

The concentration curve of the solution is monotone increasing, considering the path of the liquid stream (Fig. 21). The biggest jump in percentage concentration occurs in the second effect $(69 \%)$, then in descending order, the third effect (51\% ), the first $(45 \%)$ and the fourth $(34 \%)$.

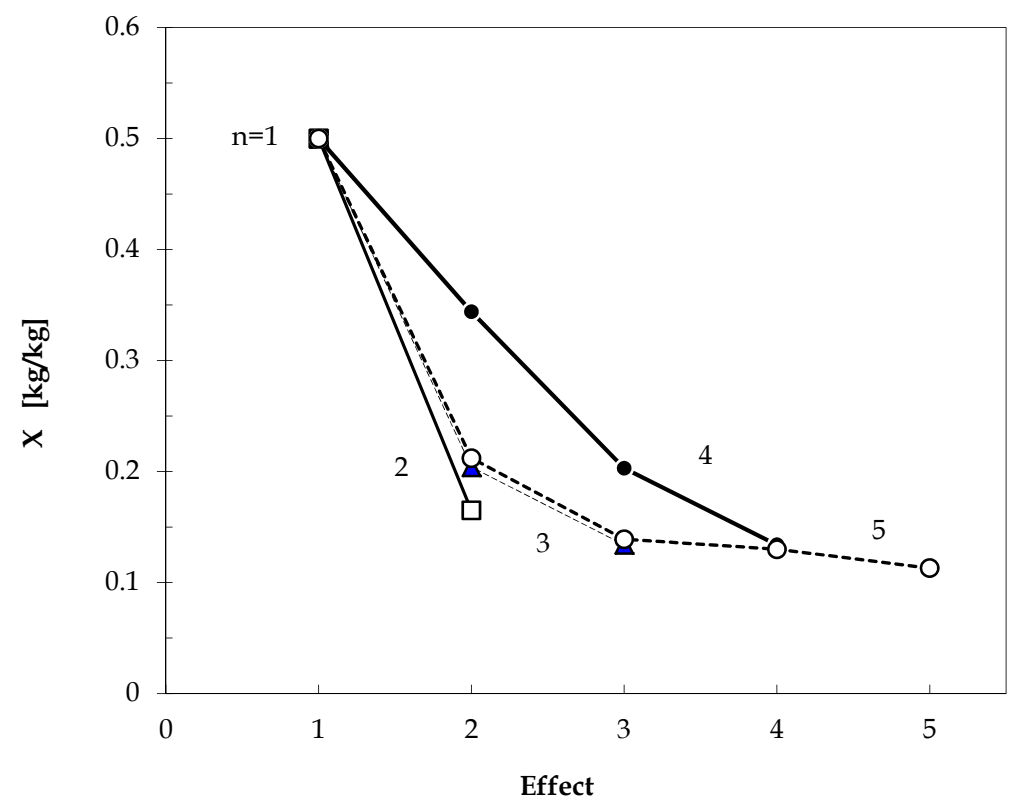

Fig. 21. Concentration profiles in the 1 to 5-effect MEES

The recent analysis of incremental concentration, the carried out for the steam produced in the effects, and the biggest jump thermal observed in effect 2 of the Optimal MEES show the importance of this effect. Its presence is the root cause of the improvement achieved in SO. This is achieved, thanks to the optimal design of the MEES, which allows an adequate relationship of the variables that define the system.

\subsection{Case III. Temperature of the weak solution lower than strong solution $\left(T_{F}<T_{P}\right)$}

\subsubsection{Uniqueness of the cost curves}

This case presents great similarity with the Case II. The optimal effect is the same (4) and intermediate structures found for $\mathrm{n} \leq 4$ are almost identical. The best configuration for the liquid stream, given by $\{4,3,2,1\}$, as in Case II, use live steam to heat the first two effects. 
Evolution of cost curves show a singularity with respect to the previously analyzed cases. Now, to increase the number of effects to reduce the TAC, the consumption of live steam begins to increase (Fig. 22) rather than continue to decline with the addition of a new effect, and the cost of the effects decreasing, rather than continue to increase. Isn't traditional behavior: a curve monotone decreasing for the cost of the live steam and one monotone increasing for the cost of the effects. Here is not complied with this scheme because of the significant reduction of the $U$ coefficient and the high increase of the boiling point (BPE) in the effects of greater concentration. It is now "pays" with live steam part of the savings in the areas of effects.

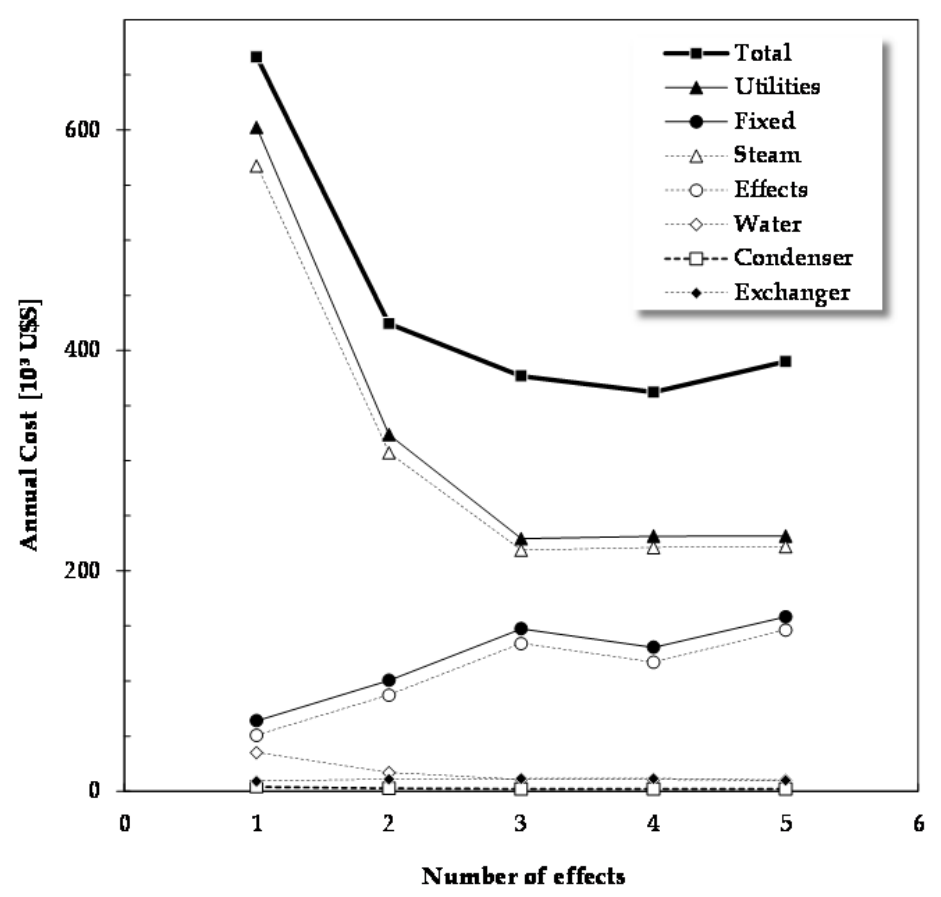

Fig. 22. Evolution of the TAC and its component terms with the number of effects (Case III).

\subsubsection{Structure and distribution of temperature, concentration and heat transfer area}

A structural analysis allows us to appreciate that the cuadruple-effect MEES results have added an effect, between the first and the second of the triple-effect MEES (Figs. 23 and 24, Table 2.).

Looking to reduce the total cost, the new effect requires one of the lowest values of area of heat transfer (Fig. 25). For this purpose, it operates with a large temperature difference; almost double that for the remaining effects (Fig. 26). On the other hand, contrary to expectations, their presence causes a slight increase in the consumption of live steam and allows at the same time, an increase in the thermal jump in the last two effects of, approximately, $6^{\circ} \mathrm{F}\left(3.3^{\circ} \mathrm{C}\right)$. 


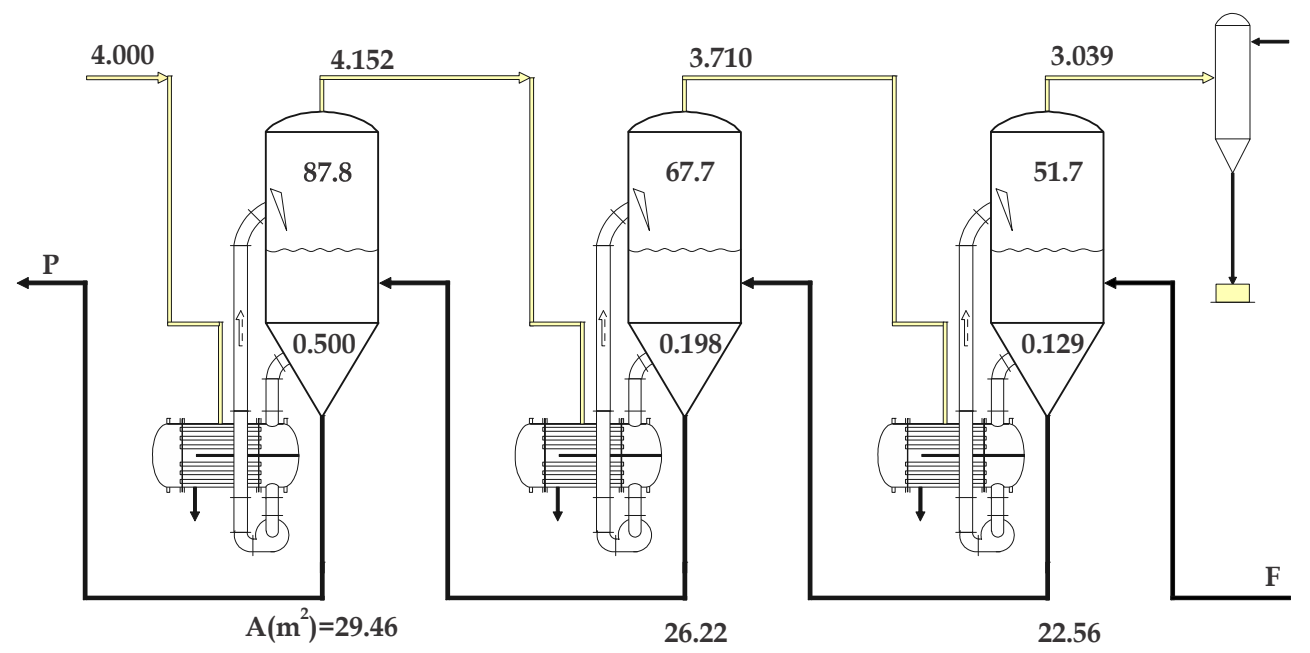

Fig. 23. Optimal Structure for three effects. (Local optimun).

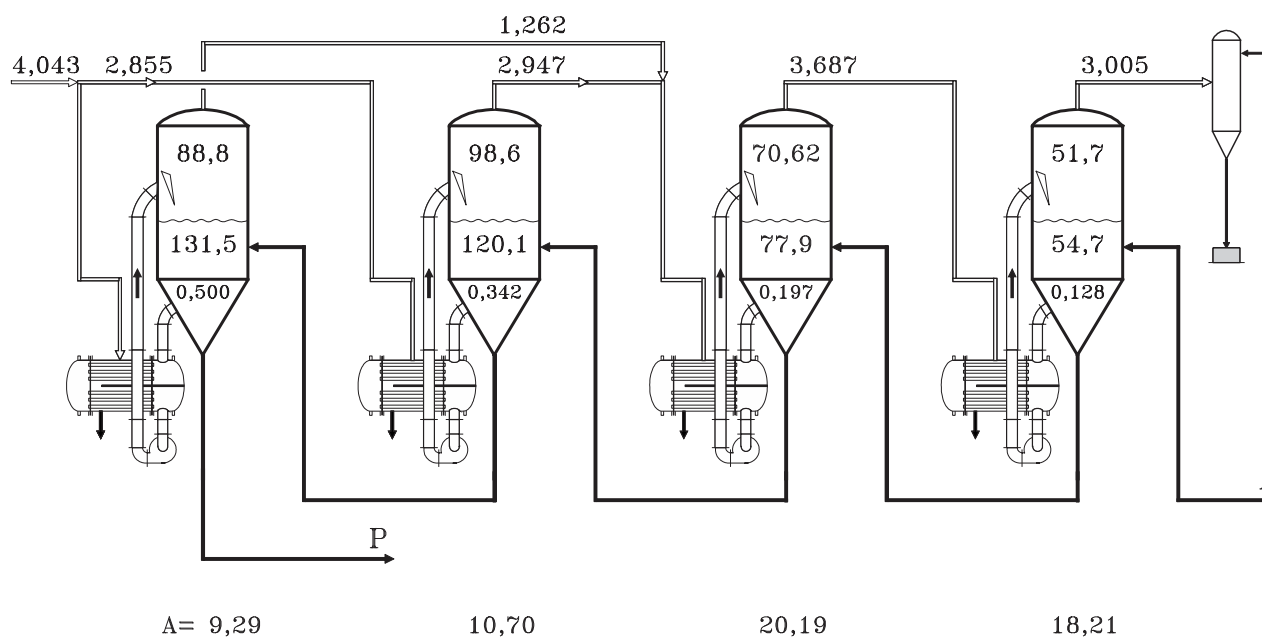

Fig. 24. Optimal Structure for four effects. (Optimal Solution). 


\begin{tabular}{|c|c|c|c|c|c|c|c|}
\hline \multicolumn{8}{|c|}{ Alternative Optimal Solutions (Case III) } \\
\hline \multicolumn{8}{|c|}{ Equal area effects MEES: SA } \\
\hline Effect & $\mathbf{T}$ & Tv & Vs & $\mathbf{L}$ & $\mathbf{V}$ & $\mathbf{X}$ & $\mathbf{F}$ \\
\hline (i) & \multicolumn{2}{|c|}{$\left[{ }^{\circ} \mathrm{C}\right]$} & \multicolumn{3}{|c|}{$\left[10^{3} \mathrm{~kg} / \mathrm{h}\right]$} & {$[\mathrm{kg} / \mathrm{kg}]$} & {$\left[\mathrm{m}^{2}\right]$} \\
\hline 1 & 137.99 & 94.92 & 4.105 & 0 & 3.232 & 0.500 & \\
\hline 2 & 128.93 & 107.28 & 0 & 0 & 2.979 & 0.340 & 15.33 \\
\hline 3 & 80.62 & 73.39 & 0 & 0 & 3.665 & 0.195 & \\
\hline 4 & 54.72 & 51.67 & 0 & 13.626 & 2.971 & 0.128 & \\
\hline \multicolumn{8}{|c|}{ Backward feed MEES. Optimal area effects: BF } \\
\hline Effect & $\mathbf{T}$ & $\mathbf{T v}$ & Vs & $\mathbf{L}$ & $\mathbf{V}$ & $\mathbf{X}$ & $\mathbf{F}$ \\
\hline 1 & 130.40 & 87.83 & 4.000 & 0 & 3.232 & 0.500 & 29.47 \\
\hline 2 & 74.99 & 67.71 & 0 & 0 & 3.710 & 0.198 & 26.22 \\
\hline 3 & 54.76 & 51.67 & 0 & 13.626 & 3.039 & 0.129 & 22.57 \\
\hline \multicolumn{8}{|c|}{ Backward feed MEES. Equal area effects: BFA } \\
\hline Effect & $\mathbf{T}$ & $\mathbf{T v}$ & Vs & $\mathbf{L}$ & $\mathbf{V}$ & $\mathbf{X}$ & $\mathbf{F}$ \\
\hline 1 & 128.39 & 85.95 & 3.984 & 0 & 4.126 & 0.500 & \\
\hline 2 & 73.12 & 65.84 & 0 & 0 & 3.719 & 0.199 & 26.54 \\
\hline 3 & 54.77 & 51.67 & 0 & 13.626 & 3.055 & 0.129 & \\
\hline \multicolumn{8}{|c|}{ Forward feed MEES. Optimal area effects: FF } \\
\hline Effect & $\mathbf{T}$ & $\mathbf{T v}$ & Vs & $\mathbf{L}$ & $\mathbf{V}$ & $X$ & $\mathbf{F}$ \\
\hline 1 & 132.77 & 127.95 & 4.822 & 13.626 & 3.517 & 0.135 & 20.37 \\
\hline 2 & 116.53 & 107.02 & 0 & 0 & 3.714 & 0.213 & 18.96 \\
\hline 3 & 91.67 & 51.67 & 0 & 0 & 3.671 & 0.500 & 32.69 \\
\hline \multicolumn{8}{|c|}{ Forward feed MEES. Equal area effects: FFA } \\
\hline Effect & $\mathbf{T}$ & $\mathbf{T v}$ & Vs & $\mathbf{L}$ & $\mathbf{V}$ & $\mathbf{X}$ & $\mathbf{F}$ \\
\hline 1 & 135.12 & 130.25 & 4.870 & 13.626 & 3.530 & 0.135 & \\
\hline 2 & 121.62 & 111.99 & 0 & 0 & 3.691 & 0.213 & 24.40 \\
\hline 3 & 91.67 & 51.67 & 0 & 0 & 3.680 & 0.500 & \\
\hline
\end{tabular}

Table 2. Results of alternative evaporation systems. (Vs: Live steam flow rate. V: Secondary Steam Flow rate) 


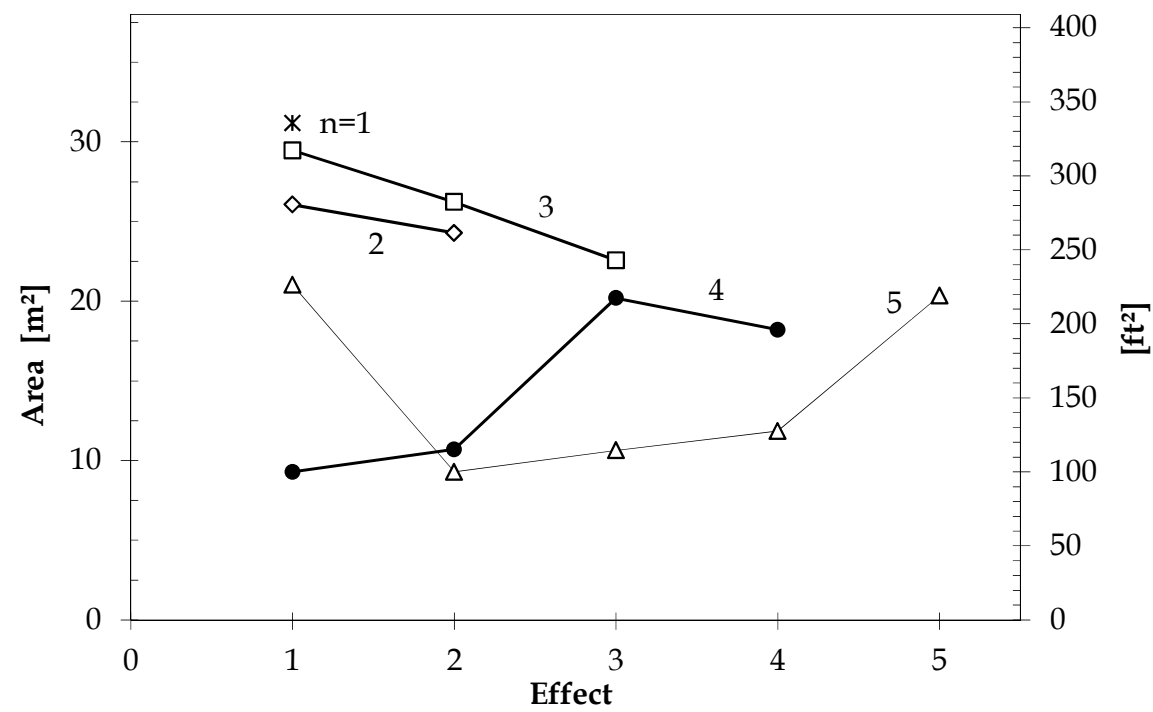

Fig. 25. Area profiles in the 1 to 5 -effect MEES.

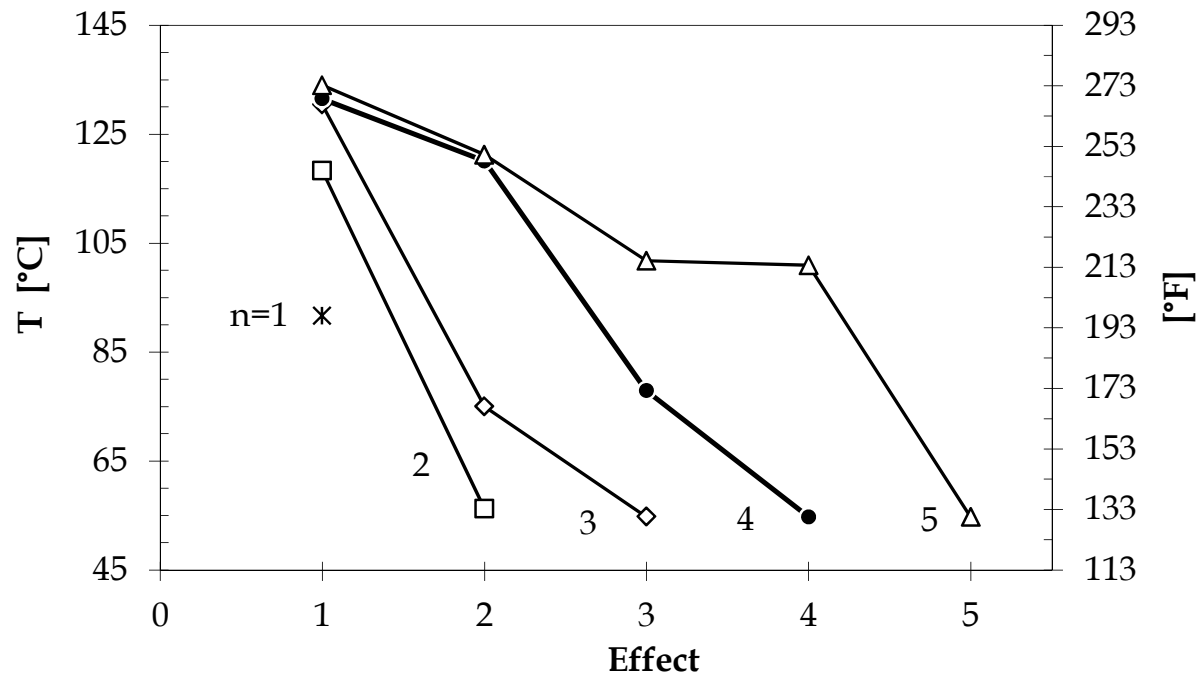

Fig. 26. Temperature profiles in the 1 to 5-effect MEES.

The net result is a drastic decrease in the area of thermal transfer, as you can see through the cost of the effects (Fig. 27). Moreover, the distribution of the heat transfer area curve changes dramatically, from being monotone decreasing for a triple-effect MEES to have a nonmonotonic behavior in the Optimal MEES. Presents a maximum in the effect 3 and a minimum in the effect 1 , where the product is removed and in which the coefficient $U$ takes its smallest value (Fig. 25). This was achieved by lowering the flow rate of the solvent evaporated in the first two effects, especially in the first (Fig. 28). 


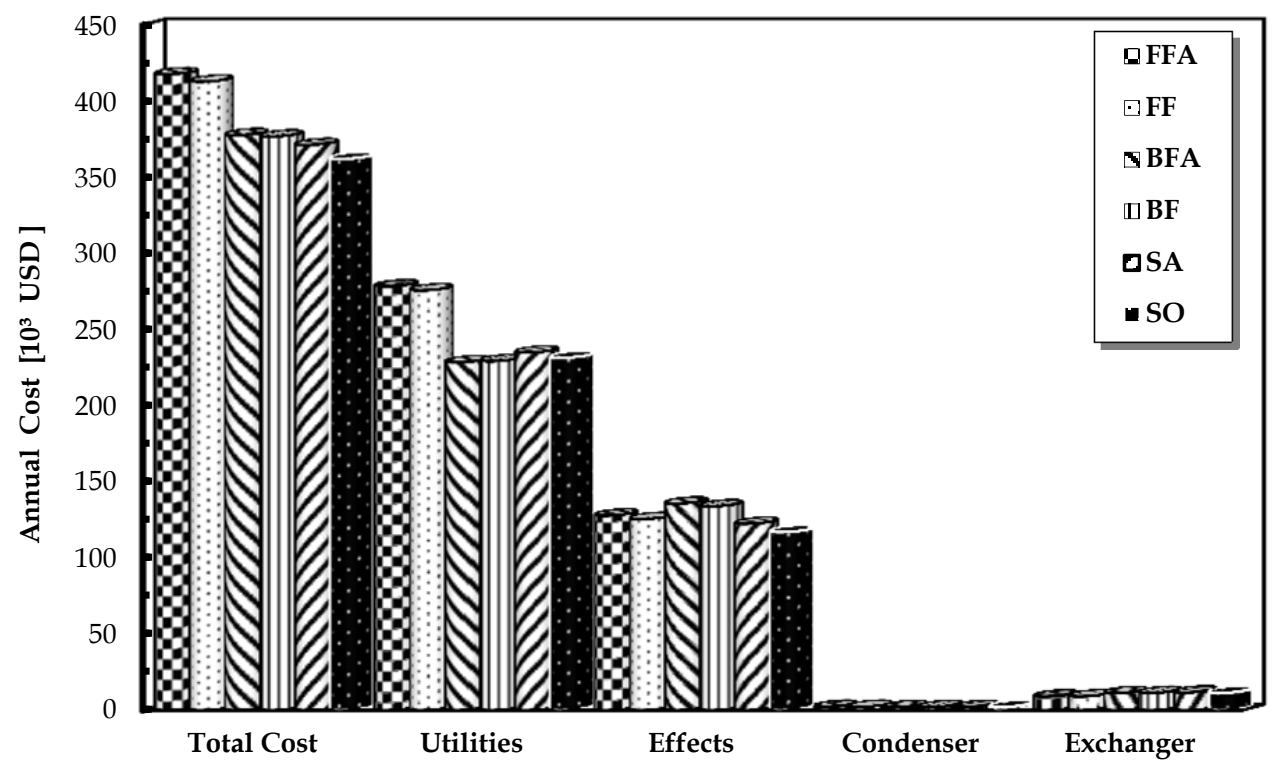

Fig. 27. Impact of the liquid flow pattern and the distribution of heat transfer area in different items of the total annual cost of the MEES (Case III).

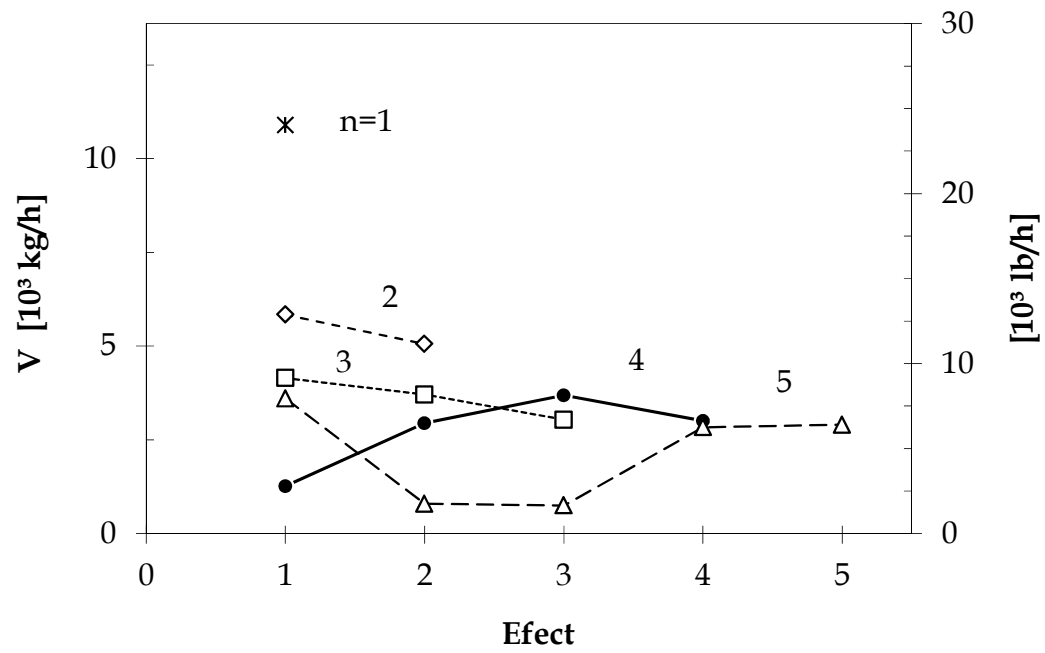

Fig. 28. Flow rate steam profiles in the 1 to 5 effect MEES.

Profile of concentration of the solution in the optimal MESS shows a non-uniform increase of concentration along the evaporator train (Fig. 29). Thus, following the path of the current liquid is seen a percentage increase of $28 \%$ in the effect $4,53 \%$ in the effect $3,73 \%$ in effect 2 and $46 \%$ in the first effect. Similarly as stated in Case II, the largest concentration jump 


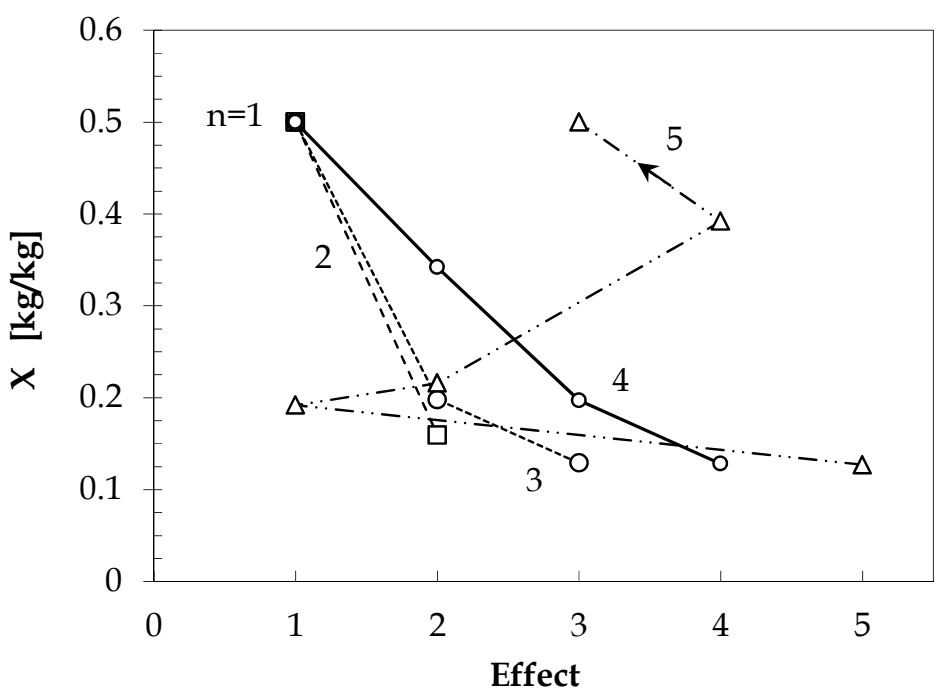

Fig. 29. Concentration profiles in the 1 to 5 effect MEES.

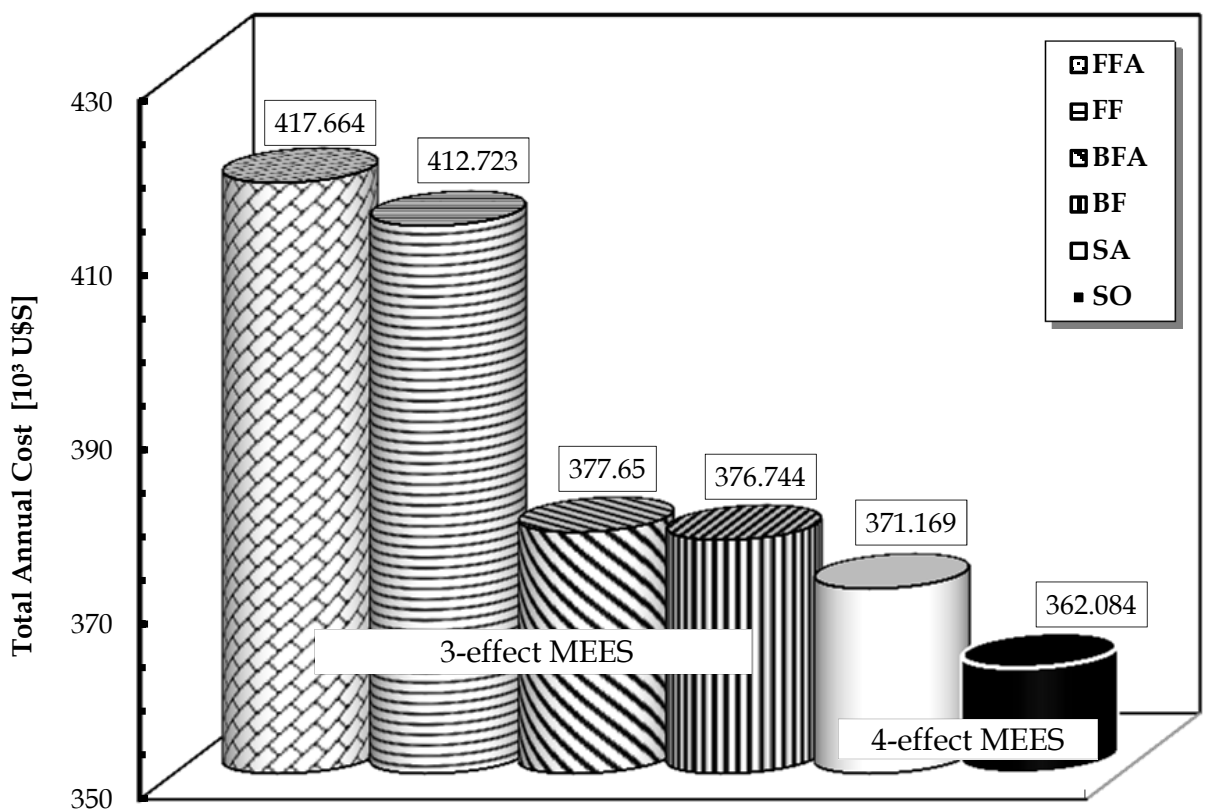

Fig. 30. Impact of the liquid and vapor flow pattern and area effects on the total annual cost of the MEES (Case III). 
occurs in effect 2, as opposed to what was observed in Case I, where the largest jump occurs in the last effect, where in addition, the product leaves.

\subsubsection{Comparison with traditional configurations}

As in the case II, the optimum number of effects of optimal MEES is four and does not match the traditionally proposed by the classic bibliography: triple-effect countercurrent (BFA). If you seek the best solution between traditional structures with effects of equal area (Table 2), again confirms the superiority of the backward feed configuration and that three is the optimal number of effects. Comparatively, FFA is $11.4 \%$ more expensive that the structure BFA (Fig. 30). If in both structures allows you to optimize the distribution of the transfer area between the different effects, the improvement is not important. Of them, the best option (BF) is $4.1 \%$ more expensive than SO. However, the best configuration for a MEES whose only structural restriction is equality of areas of its effects (SA): is backward feed $(\mathrm{BF})$.

\section{Conclusion}

In this paper, we solve the problem of designing a MEES, for the concentration of caustic soda, developing a rigorous mathematical model non-convex MINLP type and solving it using a mathematical optimizer.

Unlike previous papers, the new formulation proposal incorporates as decision variables: (a) the trajectories of the steam and liquid flows along the evaporator train whose correct choice determines, in the opinion of different authors, as has been demonstrated in the resolution of the example here presented, the level of operational costs and investment of the MEES. It is also considered (b) the number of effects of the MEES, as was proved in the results presented is another critical design decision and (c) heat transfer area in each effect, without resorting to the hypothesis of equal areas on the effects that in many cases substantially increases the total cost of investment. As an evaluation criterion of alternative designs included in the solutions space of the problem, we used the total annual cost of the system of evaporation, including fixed and operational costs.

Other important aspects, not usually treated and much less simultaneously with the search of the optimal flow pattern, were considered such as:

the rise of the boiling point of the solution and its dependency on temperature and concentration of the same, the variation of the overall heat transfer coefficient along the train following changes in the concentration and the temperature of each effect and the functional dependence of the heat of non-ideal solution with the concentration and temperature.

In addition, we studied other variants non-conventional design that arise by allowing: feed in parallel of the weak solution to two or more effects of the evaporator train, the entry of two or more liquid streams (even of different concentration) to a given effect and the derivation of a liquid solution branch around an effect to avoid its treatment in the same.

A serious drawback found in the resolution of the mathematical model is the presence of many stationary points (optimal local), and also the great influence of the initial point. 
It has been found that in order to obtain the optimal design of lower total cost annual: (i) not always steam flow pattern should be the traditional unifilar cascade, could be useful to feed steam live in more than one effect, (ii) the heat transfer areas do not necessarily have to be equal, (iii) the fresh feed stream should not always come in the last effect evaporation train.

However, the synthesis of the optimal MEES only be achieved if you are optimized simultaneously structural, parametric, and operation variables.

\section{Acknowledgment}

I thank to SeCTER for their help in research.

I thank Liliana, my dear sister, for her love and permanent support throughout my life.

\section{References}

Foust, Alan S., Principles of Unit Operations, Second Ed. C. Wiley, New York, 1980.

Geankoplis, Ch. J., Transport Processes and Unit Operations, 2nd. Edition, 495-501, 1983.

Hillebrand Jr., J. B. \& Westerberg, A.W., The Synthesis of Multiple-Effect Evaporator Systems Using Minimum Utility Insights - I. A Cascaded Heat Representation Computers \& Chemical Engineering, Vol. 12, pp. 611-624, 1988.

Horvath, A. L., Handbook of Aqueous Electrolyte Solutions, Physical Properties, Estimation and Correlation Methods, Wiley, C. New York, 1985.

Irahola Ferreira, Jaime A., \& Jaime Cerdá. Optimal Synthesis Of A Multiple-Effect Evaporator System. Fifth International Symposium On Process Systems Engineering (PSE), Korea, 1994.

Irahola Ferreira, Jaime A., \& Jaime Cerdá. Síntesis Optima de un Sistema de Evaporación Multiefecto para la Concentración de Licor de Caña de Azúcar. IX Simposio Internacional en Aplicaciones de Informática. Infonor'96. Antofagasta. Chile. 1996.

Irahola Ferreira, Jaime A., Aplicación para Formular y Resolver Modelos Matemáticos de Sistemas de Evaporación Multiefecto. Información Tecnológica. Chile, 2008

Kern, D. Q. Process Heat Transfer. McGraw-Hill, New York .pp 375 - 452, 1999.

Maloney. James O. Perry's Chemical Engineers Handbook, 8th Edn. McGraw-Hill, New York 2008.

Nishitani, H. \& Kunugita, E., The Optimal Flow-Pattern of Multiple Effect Evaporator Systems, Computers \& Chemical Engineering, Vol. 3 , pp. 261-268, 1979.

Peters, Max Stone Klaus D. Timmerhaus. Plantdesign and economics for chemical engineers. McGraw-Hill, Inc. Singapore, ISBN 0-07-100871-3, 1991.

Standiford, Ferris C. Jr., W. L. Badger, Evaporation. Chem. Engng, 70, 158-176, 1963.

Westerberg, A.W. \& Hillebrand Jr., J. B. The Synthesis of Multiple-Effect Evaporator Systems Using Minimum Utility Insights - II. Liquid Flow-Pattern Selection. Computers $\mathcal{E}$ Chemical Engineering, Vol. 12, pp. 625-636, 1988. 


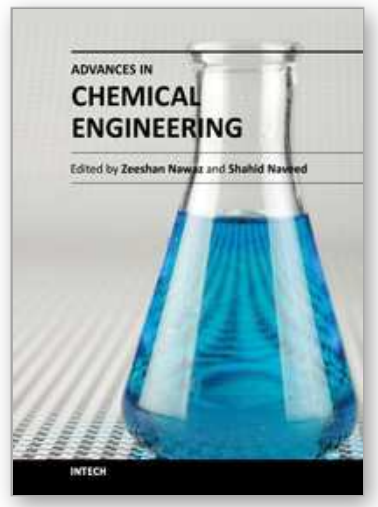

\author{
Advances in Chemical Engineering \\ Edited by Dr Zeeshan Nawaz
}

ISBN 978-953-51-0392-9

Hard cover, 584 pages

Publisher InTech

Published online 23, March, 2012

Published in print edition March, 2012

Chemical engineering applications have been a source of challenging optimization problems in terms of economics and technology. The goal of this book is to enable the reader to get instant information on fundamentals and advancements in chemical engineering. This book addresses ongoing evolutions of chemical engineering and provides overview to the sate of the art advancements. Molecular perspective is increasingly important in the refinement of kinetic and thermodynamic molding. As a result, much of the material was revised on industrial problems and their sophisticated solutions from known scientists around the world. These issues were divided in to two sections, fundamental advances and catalysis and reaction engineering. A distinct feature of this text continues to be the emphasis on molecular chemistry, reaction engineering and modeling to achieve rational and robust industrial design. Our perspective is that this background must be made available to undergraduate, graduate and professionals in an integrated manner.

\title{
How to reference
}

In order to correctly reference this scholarly work, feel free to copy and paste the following:

Jaime Alfonzo Irahola (2012). Optimal Synthesis of Multi-Effect Evaporation Systems of Solutions with a High Boiling Point Rise, Advances in Chemical Engineering, Dr Zeeshan Nawaz (Ed.), ISBN: 978-953-51-0392-9, InTech, Available from: http://www.intechopen.com/books/advances-in-chemical-engineering/optimalsynthesis-of-multi-effect-evaporation-systems-of-solutions-with-a-high-boiling-point-rise

\section{INTECH}

open science | open minds

\author{
InTech Europe \\ University Campus STeP Ri \\ Slavka Krautzeka 83/A \\ 51000 Rijeka, Croatia \\ Phone: +385 (51) 770447 \\ Fax: +385 (51) 686166 \\ www.intechopen.com
}

\author{
InTech China \\ Unit 405, Office Block, Hotel Equatorial Shanghai \\ No.65, Yan An Road (West), Shanghai, 200040, China \\ 中国上海市延安西路65号上海国际贵都大饭店办公楼 405 单元 \\ Phone: +86-21-62489820 \\ Fax: $+86-21-62489821$
}


(C) 2012 The Author(s). Licensee IntechOpen. This is an open access article distributed under the terms of the Creative Commons Attribution 3.0 License, which permits unrestricted use, distribution, and reproduction in any medium, provided the original work is properly cited. 